\title{
Transparency and Liquidity Uncertainty in Crisis Periods
}

\author{
Mark Lang \\ University of North Carolina at Chapel Hill \\ Mark Maffett \\ University of North Carolina at Chapel Hill \\ Kenan-Flagler Business School \\ 300 Kenan Center Drive \\ Campus Box 3490, McColl Building \\ Chapel Hill, NC 27599
}

January 2011

\begin{abstract}
We document, for a global sample, that firms with greater transparency (based on accounting standards, auditor choice, earnings management, analyst following and forecast accuracy) experience less liquidity volatility, fewer extreme illiquidity events and lower correlations between firm-level liquidity and both market liquidity and market returns. Results are robust to numerous sensitivity analyses, including controls for endogeneity and propensity matching. Results are particularly pronounced during crises, when liquidity variances, covariances and extreme illiquidity events increase substantially, but less so for transparent firms. Finally, liquidity variance, covariance and the frequency of extreme illiquidity events are all negatively correlated with Tobin's Q.
\end{abstract}

JEL Classification: G01, G15, G30

Keywords: Liquidity, Transparency, Financial Crises, Commonality, International Accounting.

We thank workshop participants at Cornell University, MIT, University of Texas, Tilburg University, the 2010 Journal of Accounting and Economics Conference, the Bundesbank-FRIAS-RFS Conference on "Liquidity and Trust in Incomplete Markets," the Third Erasmus Liquidity Conference, and the 2010 Global Issues in Accounting Conference at UNC for helpful comments, as well as Bob Holthausen (editor), Ronnie Sadka (JAE discussant), an anonymous reviewer, Dan Amiram, Lieven Baele, Robert Bushman, Mathijs van Dijk, Joseph Gerakos, John Hand, Andrew Karolyi, Katie McDermott and Edward Owens. Mark Maffett gratefully acknowledges funding from the Deloitte Foundation. E-mail correspondence to Mark Lang at Mark_Lang@unc.edu. 


\section{Introduction}

A substantial body of research demonstrates that, all else equal, investors prefer stocks that are liquid and that transparency has the potential to improve liquidity [for a summary see, Amihud, Mendelson and Pedersen (2005)]. However, the concern for investors is broader than simply the average level of liquidity because what matters is the liquidity at the time they choose to transact. Investors prefer firms with relatively predictable liquidity because they are able to better anticipate the likely trading costs associated with transacting. ${ }^{1}$ To the extent a stock's liquidity is variable, it increases the uncertainty attached to a position and limits a potential investor's flexibility. In extreme cases, stocks may be subject to periods where liquidity suddenly evaporates, effectively eliminating the opportunity for a trader to enter or exit a position at all. For example, Moorthy (2003) discusses the possibility of "liquidity black holes" in which liquidity freezes in the absence of investors willing to take the other side of positions, and fund managers faced with redemptions are forced to either offload positions at fire-sale prices or unbalance their portfolios by selling their most liquid securities.

Not only does the variability of liquidity matter, but its timing matters as well. Illiquidity is of special concern if it tends to occur at inopportune times. If illiquidity in a given stock is highly correlated with illiquidity in other stocks or with market returns, it is likely to be expensive to sell at exactly the time the investor wants to liquidate the position. Research such as Brunnermeier and Pedersen (2009) [hereafter referred to as 'BP (2009)'] suggests that firm-level liquidity will naturally be positively correlated with overall market liquidity and with market returns because traders' ability to provide liquidity is a function of the availability of funds, which can induce co-movement in liquidity across stocks as well as co-movement between firmspecific liquidity and market returns. Acharya and Petersen (2005) decomposes the CAPM beta to show that cost of capital is a function of the covariance between firm liquidity and both market returns and market liquidity. They provide empirical evidence that U.S. stocks that maintain a relatively constant level of liquidity when overall markets become illiquid, or when

\footnotetext{
${ }^{1}$ Persaud (2003) notes, "there is a broad belief among users of financial liquidity - traders, investors and central bankers - that the principal challenge is not the average level of financial liquidity, but its variability and uncertainty.” Similarly, McCoy (2003) states that, “As important as the level of liquidity is its uncertainty. In an age where there is intolerance for risks that cannot be quantified, investors may avoid markets altogether where liquidity is uncertain."
} 
stock returns are negative, enjoy a lower cost of capital because investors are willing to pay more for shares if they expect to be able to exit positions at a relatively low cost during these periods.

While liquidity variance and covariance are important in general, they can be particularly important during crisis periods as illustrated in the recent financial market turmoil. For example, research such as BP (2009) suggests that funding constraints, and hence firm-specific liquidity co-movement with market liquidity and market returns, will be particularly pronounced when market returns are negative and, consequently, available capital to provide liquidity is limited. Empirically, Hameed, Kang and Viswanathan (2010) provides evidence that liquidity decreases and comovement increases during market downturns, consistent with a reduction in liquidity supply when the market drops.

As discussed in more detail in the third section, by reducing uncertainty about intrinsic value, transparency has the potential to affect liquidity variability and co-movement. Models in papers such as BP (2009) and Vayanos (2004) show liquidity can dry up because of a "flight to quality," where liquidity providers flee from assets with high levels of uncertainty about fundamental value. To the extent that transparency provides information about, for example, future cash flows, it reduces uncertainty about intrinsic value, potentially reducing the sensitivity of liquidity to market shocks. Further, transparency effects are likely to be particularly pronounced during crisis periods. During large market downturns, liquidity tends to be particularly fragile because capital is scarce and overall uncertainty is high. As a result, opaque stocks will be particularly sensitive to the effects of exogenous shocks to liquidity. In the recent financial crisis, for example, liquidity variability was more pronounced for asset classes with greater uncertainty. In addition, for transparent stocks, firm-level liquidity is less likely to be subject to market-wide liquidity shocks because more firm-specific information permits investors to differentiate between stocks [Persaud (2003)]. Similarly, Vayanos (2004) suggests that liquidity providers become more risk averse in the face of uncertainty about fundamental asset values. To the extent that transparency reduces uncertainty it has the potential to reduce the tendency to withdraw liquidity during market downturns. 
While there are conceptual reasons to believe liquidity variance and covariance could be affected by transparency, and theoretical and empirical evidence showing that liquidity covariance is an important component of cost of capital, we are unaware of any empirical research that explicitly examines the link between firm-level transparency and liquidity variance and covariance. That is the focus of our study.

We consider five firm-level measures of transparency-auditor choice, accounting standard choice, earnings management, analyst following and analyst forecast accuracy. These measures have been used in prior research to capture aspects of firms' information environments [e.g., Lang, Lins and Maffett (2010)], and tend to vary substantially across firms. To ensure that our results do not simply reflect omitted correlated variables, we control for fixed country- and yearlevel effects in our primary analyses along with a range of factors from the prior literature. We also report results using firm fixed effects to control for other firm-level differences.

Our study uses a broad sample of international firms from thirty-seven countries. We focus on a global sample for three main reasons. First, international firms are more likely to vary widely in terms of transparency as reflected in differences in accounting standards, auditor quality, earnings management, analyst following, investor protection, institutional holdings and countrylevel transparency, as well as in liquidity. Second, we are interested in crisis periods and a crosscountry sample provides a much wider set of economic environments. Third, the international setting seems inherently interesting because the effects of the recent financial crisis varied markedly across economic settings, and the precipitating factors are not well understood.

We use the Amihud (2002) price impact of trade measure to capture liquidity. Price impact is a major consideration to investors contemplating an investment in a stock because it reduces the potential return by increasing roundtrip transactions costs. Further, this measure is consistent with theoretical research such as Grossman and Miller (1988) and BP (2009) which defines liquidity based on price deviations from fundamental value as a result of buying and selling pressure. 
We begin by examining the relation between transparency and the volatility of liquidity. As predicted, we find that liquidity volatility is significantly negatively correlated with each of our transparency variables. For parsimony, and because the individual transparency measures are unlikely to be independent, in subsequent analyses we combine the five variables into an aggregate transparency measure. Next, we examine the relation between this aggregate measure of transparency and the incidence of extreme illiquidity, measured by the skewness of liquidity as well as by a measure of "liquidity black holes" (defined as cases in which transactions costs are at least 50 times their normal levels for a given country). We find that stocks with greater transparency experience fewer cases of extreme illiquidity as reflected in both measures. In our third set of analyses, we investigate the relation between transparency and liquidity covariance with market liquidity and market returns. We find that transparent firms experience lower covariance between their liquidity and both market liquidity and market returns. These findings suggest transparent firms are less likely to be illiquid at inopportune times, such as when market liquidity is low and market returns are negative.

In our next set of analyses, we investigate variation in the relation between transparency and liquidity variability and covariability based on the country-level institutional environment. Prior literature [e.g., Ball (2001) and Lang, Lins and Miller (2004)] suggests there are likely to be countervailing effects depending on whether firm-level transparency complements or substitutes for the quality of country-level regulatory oversight. Consistent with predictions, we find that international accounting standards and 'Big-5' auditors are most important in environments with stronger overall investor protection and enforcement, while analyst following, forecast accuracy and earnings management are more important in countries with weaker institutions.

Next, we examine the effect of crisis periods on the relation between transparency and liquidity variability and covariability. Following prior literature [e.g., Hameed et al. (2010)], we define a crisis period as a month in which a country's stock market falls by more than 1.5 times its historical standard deviation. This definition captures the notion that liquidity providers are more likely to be financially constrained when their own capital has decreased due to a market downturn and it is more difficult to borrow from funding sources due to increased uncertainty. We find that the negative relation between transparency and liquidity variability, extreme 
illiquidity events and the correlation between firm-level liquidity and both market returns and market liquidity is significantly more pronounced during crisis periods. In addition, we find that transparency mitigates the increase in CAPM beta which tends to occur during down markets [Ang and Chen (2002)]. Intuitively, this result suggests transparency lessens the impact of liquidity on return covariability during crises. Splitting our market downturn indicator based on more and less extreme crises according to the magnitude of the stock price drop, we find that the relation between transparency and all five measures of liquidity variability and covariability is substantially stronger the larger is the crisis. Overall, these results are consistent with the theoretical and intuitive notion that transparency matters most to liquidity variability and covariability during crisis periods, and that the effect is larger for greater crises.

Finally, we investigate the association between Tobin's Q and our liquidity variability and covariability measures. To this point, we have implicitly assumed that liquidity variability and covariability are important to investors. We find that each of our liquidity uncertainty measures is strongly and incrementally negatively correlated with firm value, suggesting that liquidity variability and covariability are important to investors and that none of our variability measures subsumes any of the others. Moreover, we document that the effect of transparency on valuation through liquidity uncertainty appears to be at least as important as the effect of transparency on valuation through the level of liquidity.

Overall, our results suggest that transparency has a strong and consistent negative association with each of our proxies for liquidity uncertainty - liquidity volatility, liquidity skewness, the frequency of extreme illiquidity events, the covariance of firm-level liquidity with market liquidity, and the covariance of firm-level liquidity with market returns - and that each of these measures is negatively correlated with firm value. Moreover, these effects are consistent for the vast majority of our sample countries and appear large enough to be economically important. While it is dangerous to draw causal links, the inclusion of a wide range of controls, including country and year fixed effects, lessens the probability that omitted correlated variables affect our inferences. Results are also robust to firm fixed effects, alternate measures of liquidity, specifications based on changes and a two-stage analysis which instruments transparency to address potential endogeneity. In addition, the fact that our results are predictably stronger 
during crises suggests that the results do not simply reflect systematic differences in the variability and covariability of underlying economics for the sample firms, since it is difficult to imagine alternative reasons why liquidity variance and covariance shifts would be associated with transparency particularly in crisis periods. Further, our liquidity variables are measured over relatively short windows and our transparency variables are lagged, reducing the likelihood of reverse causality. Finally, our findings are consistent with theoretical research. Nonetheless, conclusions on causality should be drawn with caution. ${ }^{2}$

In the next section, we discuss the related literature. In Section 3, we present our primary hypotheses. We discuss our data and empirical approach in Section 4. In Section 5, we provide empirical results. Section 6 concludes.

\section{Related Literature}

Our primary interest is in the relation between firm-level transparency and the variability and covariability of firm-level liquidity. While liquidity uncertainty and covariability are of interest to investors, managers and regulators, there is, to our knowledge, no direct research on their relation to firm-level transparency. However, there are several streams of literature that provide background and motivation for our study.

First is the literature on transparency and the level of liquidity, surveyed in Amihud, Mendelson and Pedersen (2005) and Lang and Maffett (2010), which investigates the role of transparency in mitigating information asymmetry. Closely related is the theoretical research investigating liquidity variability and covariability, such as BP (2009) and Vayanos (2004), which suggests mechanisms that cause liquidity to fluctuate, evaporate suddenly and covary with market-wide returns and market-wide liquidity. Further, Acharya and Pedersen (2005) provides theoretical

\footnotetext{
${ }^{2}$ A reasonable question is why, if transparency provides benefits to shareholders, all firms wouldn't choose to be more transparent. However, there are direct costs (e.g., for higher quality auditors, application of international accounting standards and improved investor relations) and indirect costs (e.g., loss of private control rights for management, large blockholders and other stakeholders) associated with maintaining high levels of transparency [see Leuz, Nanda and Wysocki (2003) and Lang et al. (2010) for further discussion].
} 
and empirical evidence that the covariability of firm-level liquidity with market liquidity and market returns are systematic risk factors that are components of cost of capital. ${ }^{3}$

In terms of empirical research, Pastor and Stambaugh (2003) finds that the correlation between firm-level returns and market-wide liquidity is a priced risk factor, and $\mathrm{Ng}$ (2010), using a U.S. sample, investigates the potential role of information in that relation. ${ }^{4}$ These papers consider a fundamentally different question than ours in the sense that they focus on firm-level returns; neither investigates variation and covariation in firm-level liquidity, which is the focus of our analysis. Empirically, the underlying constructs are also different. We document that the correlations between the co-movement in firm-level returns and market liquidity from Pastor and Stambaugh (2003) and Ng (2010) and the liquidity co-movements we examine are 0.02 for market returns and 0.08 for market liquidity. Moreover, controlling for their measures does not change any of our conclusions, and our Tobin's Q results confirm that the liquidity variability and covariability measures we consider have separable and incremental effects on firm value relative to their measures. ${ }^{5}$

Third, there are country-level studies comparing cross-country return and liquidity co-movement. Brockman and Chung (2002) documents that exchange-level sources explain 39 percent of total cross-country commonality in liquidity, while global sources represent 19 percent. Qin (2008) documents significantly higher liquidity commonality in emerging markets and shows that liquidity commonality is more affected by market prices than individual stock prices, consistent with the effects of inventory risk. Morck, Yeung and Yu (2000) documents greater

\footnotetext{
${ }^{3}$ Kamara, Lou and Sadka (2008) documents that the cross-sectional variation of liquidity commonality increased over the period 1963-2005, which they relate to patterns in institutional ownership. Their results suggest that it has become more difficult to diversify systematic risk and aggregate liquidity shocks, potentially increasing the fragility of the U.S. equity market. In addition, Lou and Sadka (2010) provides evidence that stocks with high liquidity betas underperform the market.

${ }^{4}$ Hutton, Marcus and Tehranian (2009) finds that opacity, as measured by earnings management, is associated with higher synchronicity in returns for U.S. firms and that opaque firms are more prone to stock price crashes, although the relation dissipated after passage of Sarbanes-Oxley. Giles (2010) conducts an intra-daily analysis of market crashes and finds that stock prices and order depth decline more and stock prices are more volatile for firms with poor accounting quality.

${ }^{5}$ Also, the fundamental underlying economic drivers of the correlation between firm-level returns and market liquidity likely differ from those that drive the correlations between firm-level liquidity and market liquidity and returns. As Ng (2010) notes, the correlation between firm-level returns and market liquidity likely reflects changes in investor risk aversion and portfolio allocations during periods of market illiquidity, while BP (2009) suggests that firm-level liquidity variability and covariability reflect the capital and funding available to liquidity providers.
} 
"synchronicity" in returns for low-income, relative to high-income, economies, which appears to be associated with property rights. Jin and Myers (2006) develops a model to explain return synchronicity and link return comovement to control rights and information. Finally, Karolyi, Lee and Van Dijk (2010) evaluates country-level determinants of commonality in liquidity across countries and over time, and argues that results are more consistent with demand-side explanations (e.g., investor protection, trading by international and institutional investors, and investor sentiment) than supply-side explanations (e.g., the funding liquidity of financial intermediaries). While these analyses are informative, country-level factors are largely outside of an individual firm's control and the inherent mix of factors at work at the country level makes it more difficult to tease out the determinants of the underlying relations.

To summarize, while there are related empirical literatures, none addresses the central question of our paper which is whether, when and to what extent firm-level transparency mitigates the variability and covariability of firm-level liquidity. Given the potential significance of this issue for a wide range of constituents, we believe this is an important contribution to the literature.

\section{Hypothesis Development}

Although we do not view our analysis as a test of a particular theory, our hypotheses are motivated by the intuition underlying papers such as Grossman and Miller (1988) and BP (2009), which theoretically model and analyze factors that affect the level of an asset's liquidity and its variance and covariance with macroeconomic conditions. A common theme is the notion that investors value immediacy, which speculators provide in exchange for a discount to compensate them for providing continuity in the market and taking the risk associated with holding a position until the arrival of the ultimate buyer. These speculators rely on a mix of their own capital and leverage to finance their trades. Liquidity is reflected in the discount they charge for providing immediacy, which is a function of the level of uncertainty about the fundamental value of the stock coupled with factors such as their level of risk aversion and the availability of funding. 
While the theoretical literature does not explicitly consider the role of transparency, a potential link exists to the extent that transparency reduces uncertainty about fundamental value. ${ }^{6}$ Specifically, for stocks about which there is more uncertainty about intrinsic value, liquidity tends to be less predictable and more sensitive to factors such as economy-wide uncertainty, funding availability and risk aversion, leading to our first hypothesis:

H1: The lower is firm-level transparency, the greater is the variability of liquidity.

Further, papers such as BP (2009) and Vayanos (2004) suggest that liquidity in assets with a great deal of uncertainty about fundamental value can be fragile in the sense that illiquidity can spiral upwards making trades prohibitively expensive. ${ }^{7}$ This leads to our second hypothesis:

H2: The lower is firm-level transparency, the more frequent are extreme illiquidity events.

Variability of liquidity would be less of an issue if liquidity changes were uncorrelated across securities. However, because shocks to funding, uncertainty and risk aversion tend to be shared across liquidity providers, there is comovement in liquidity across assets, particularly for stocks with greater uncertainty about intrinsic value since they are more sensitive to liquidity shocks. We investigate this possibility in test of our third hypothesis:

H3: The lower is firm-level transparency, the greater is the covariability of firm-level liquidity with market liquidity.

Because speculators are, on average, net long in the market, their capital tends to drop during market downturns. In addition, funding for liquidity providers tends to dry up during downturns because uncertainty is higher and funding is scarcer. Opaque stocks are likely to be more

\footnotetext{
${ }^{6}$ In BP (2009), for example, uncertainty about fundamental value is modeled as the exogenously-determined variance of an autoregressive conditional heteroskedasticity (ARCH) process. While transparency would not affect the underlying variance of the time series process, it can reduce uncertainty about the outcomes from that process.

${ }^{7}$ For example, in a "margin spiral" a shock to capital causes speculators to provide less liquidity, increasing the variability of share price, which leads financiers to increase margins, worsening the speculator's capital problem. Similarly, in a "loss spiral" stock price drops lead to losses in speculators' positions, reducing their capital and causing them to reduce liquidity, resulting in further price declines.
} 
affected because greater uncertainty about intrinsic value means that it is more difficult and expensive for speculators to borrow to provide liquidity and their own capital is relatively low. Therefore, liquidity tends to decrease when market returns drop, particularly for assets with greater uncertainty [BP (2009)]. This notion leads to our fourth hypothesis:

H4: The lower is firm-level transparency, the greater is the covariability of firm-level liquidity with market returns.

In addition, because liquidity is particularly sensitive to uncertainty when speculator capital is low and uncertainty is high, liquidity variability, extreme illiquidity events and liquidity covariances are expected to be particularly pronounced following sharp market downturns, leading to our fifth hypothesis:

H5: Firm-level transparency is most important to liquidity variability, extreme illiquidity and the covariation of firm-level liquidity with both market liquidity and market returns following sharp market downturns.

Finally, to the extent investors are less willing to purchase stocks with high liquidity volatility, more frequent periods of extreme illiquidity and higher correlations between firm-level liquidity and market liquidity and market returns, the share prices for those firms should be correspondingly lower, leading to our final hypothesis:

H6: Tobin's $Q$ is negatively related to the variability of liquidity, the frequency of extreme illiquidity events, the covariation between firm-level liquidity and market liquidity and the covariation between firm-level liquidity and market returns. 


\section{Research Design and Data}

\subsection{Research Design}

Firm-level transparency is inherently difficult to measure, so we consider several indicators of transparency, following Lang et al. (2010). ${ }^{8}$ Our goal is to identify firm-level features that are likely to reduce uncertainty about intrinsic value. Our first transparency variable assesses the degree to which a firm engages in discretionary earnings management. Following the procedure in Lang et al. (2010), described more fully in the Appendix, we combine two commonly used measures of earnings management: the variability of net income relative to cash flows and the correlation between accruals and cash flows [e.g., Leuz et al. (2003) and Barth, Landsman and Lang (2008)]. Following the discretionary accruals literature [e.g., Jones (1991)], we regress out a set of fundamental determinants of earnings smoothness from each of the measures (log of total assets, leverage, book value relative to market value, volatility of sales, frequency of accounting losses, length of the firm's operating cycle, sales growth, operating leverage, average cash flows from operations, year fixed effects and industry fixed effects). We use the resulting residuals to form our measure of discretionary earnings smoothness, DIS_SMTH, which is predicted to be indicative of greater earnings management and associated with greater opacity.

Second, we consider the firm's auditor. Prior literature suggests that the informativeness of accounting data is likely to be higher if the auditor is an affiliate of a global accounting firm, so we include an indicator variable, BIG5, if a firm's auditor is affiliated with a Big-5 audit firm [Francis (2004) and Fan and Wong (2005)]. ${ }^{9}$

Third, we consider accounting standards. Prior research such as Barth et al. (2008) and Bradshaw and Miller (2008) suggests that accounting quality is generally higher for firms reporting under IFRS or U.S. GAAP, so we expect greater transparency for firms that use non-local accounting

\footnotetext{
${ }^{8}$ Each of these transparency indicators likely measures the underlying theoretical construct with error. To ensure the measures reflect firm-level transparency, in an untabulated analysis we confirm that each transparency proxy is individually, and incrementally, significantly associated with the information component of the bid-ask spread.

${ }^{9}$ Because our primary data source (Datastream) maintains firm-specific auditor data for only the most current fiscal year, we collect time-series data from a variety of additional sources, including historical point-in-time data from Datastream and Compustat Global.
} 
standards. However, research such as Daske, Hail, Leuz and Verdi (2008, 2009) and Lang et al. (2010) suggests that the benefits of IFRS adoption obtain only for firms that seriously commit to the standards' implementation. Accordingly, following Lang et al. (2010), we define serious adopters (INTGAAP = 1) as firms which either mandatorily or voluntarily adopted international accounting standards and have an above-median aggregate transparency score (calculated excluding the INTGAAP variable).

Beyond accounting choices, transparency is also likely to be enhanced by analyst's information gathering and aggregation [Roulstone (2003)]. Lang et al. (2004) argues that, in an international setting, analysts play a particularly important oversight and information processing role. We therefore include ANALYST, the number of analysts forecasting the firm's earnings, as our fourth measure of transparency.

In addition to the number of analysts, the accuracy of their forecasts is likely also a function of the transparency of the firm's information environment, including both the effects of their private information acquisition as well as firms' disclosure policies. Following Lang and Lundholm (1996), we include a measure of forecast accuracy, ACCURACY, controlling for earnings surprise and forecast bias during the period, as our final measure of transparency. Our accuracy measure captures, for a given magnitude of earnings surprise and bias, the extent to which analysts are able to accurately forecast earnings.

In models testing our first hypothesis, we measure the volatility of a firm's liquidity, LIQVOL, as the monthly standard deviation of the daily Amihud (2002) price impact of trade measure $(D P I) .{ }^{10}$ The Amihud (2002) price impact measure is based on a notion of liquidity similar to that espoused in Kyle (1985) and captures the ability of an investor to trade in a stock without affecting its price. The Amihud measure has the intuitive interpretation of being an estimate of the price impact which would be associated with transacting a thousand dollars worth of stock in a given day. This is consistent with the notion in Grossman and Miller (1988) that a stock's liquidity is reflected in the extent of price pressure associated with buying and selling. A liquid

\footnotetext{
${ }^{10}$ Where LIQVOL is included as a dependent variable, we take the natural log. Logging the variable eliminates its natural skewness and makes it more appropriate for inclusion in an ordinary least squares analysis.
} 
market is one in which investors can trade with a minimal effect on price. We calculate DPI as:

$$
\frac{\left|R_{i, d}\right|}{P_{i, d} V O_{i, d}}
$$

where $R_{i, d}$ is the daily percentage price change, $P_{i, d}$ is price in $\$$ U.S., and $V O_{i, d}$ is the trading volume for stock $i$ on day $d$ (measured in thousands). Higher values of DPI indicate greater illiquidity. Following prior research [e.g., Daske et al. (2008)], we exclude zero-return days from the calculation of the monthly averages to avoid misclassifying days with no trading activity. Further, we require a minimum of 10 daily DPI observations to calculate firm-month LIQVOL.

Our second hypothesis is that lower firm-level transparency leads to more frequent extreme illiquidity events. To test this hypothesis, we use two related measures: liquidity skewness (LIQSKEW) and the probability of a firm experiencing a "liquidity black hole" (LBH). LIQSKEW is defined as the monthly skewness of our price impact of trade measure (DPI), reflecting the notion that illiquidity will be more skewed for firms with more frequent illiquidity events. $L B H$ measures the frequency with which a firm experiences an extreme increase in the cost of trading its shares and is defined as the percentage of trading days in the month during which DPI is more than 50 times the country-level median. ${ }^{11}$ Since $L B H$ is bounded by zero and one, it is not suitable for use as a dependent variable in our OLS regressions, so we use the log transformation of $L B H$ in tests of our primary hypotheses.

Our third and fourth hypotheses are that firms with lower levels of transparency experience greater commonality of liquidity with both market liquidity and market returns. To test these hypotheses, we use two measures, $\operatorname{COM}(F L, M L)$ and $\operatorname{COM}(F L, M R$, ) calculated following prior literature, such as Morck et al. (2000) and Karolyi et al. (2010), which uses the $R^{2}$ from a regression of individual stock returns on the market return as a measure of stock price co-

\footnotetext{
${ }^{11}$ Our median illiquidity measure is 0.022 , implying that a $\$ 5$ million sale would decrease share price by $0.11 \%$ (DPI has been multiplied by 1,000 for readability and dollar volume is measured in thousands). An extreme illiquidity event would be one in which the stock price decrease associated with the sale of $\$ 5$ million is 5.5\%. Clearly, the prospect of liquidating a position under such circumstances would be a troubling risk for most investors.
} 
movement within a country. To construct a monthly time-series of $C O M(F L, M L)$ for tests of our third hypothesis, we use the $R^{2}$ from the following regression (run by firm and month):

$$
\% \Delta D P I_{i, d}=\alpha_{i}+\beta_{i, 1} \% \Delta D P I_{m, d-1}+\beta_{i, 2} \% \Delta D P I_{m, d}+\beta_{i, 3} \% \Delta D P I_{m, d+1}+\varepsilon_{i, d}
$$

where $\% \Delta D P I_{i, d}$ is equal to the daily percentage change in $D P I$ for firm $i$ on day $d$ and $\% \triangle D P I_{m, d}$ is equal to the daily percentage change in DPI for the market on day $d$. We define market illiquidity at the country-level as the daily equal-weighted average DPI of the individual stocks on a given day. Following prior literature, we take the percentage change to capture innovations in illiquidity [e.g., Hameed et al. (2010)] and include one-day leading and lagging changes in market illiquidity to account for nonsynchronous trading [e.g., Jin and Myers (2006)]. We require a minimum of 10 daily observations to estimate a firm-month $R^{2}$ and a minimum of 10 firms to estimate the daily country-level average DPI. In the regression analyses, we use a log transformation because $C O M(F L, M L)$ is bounded by zero and one.

We use similar procedures to construct $\operatorname{COM}(F L, M R)$ and take the $R^{2}$ from the following regression (run by firm and month):

$$
\% \Delta D P I_{i, d}=\alpha_{i}+\beta_{i, 1} \operatorname{MKTRET}_{m, d-1}+\beta_{i, 2} \operatorname{MKTRET}_{m, d}+\beta_{i, 3} M_{K T R E T_{m, d+1}}+\varepsilon_{i, d}
$$

where $\% \triangle D P I_{i, d}$ is as defined above and $M K T R E T_{m, d}$ is the daily country-level market return, calculated using the relevant Datastream index.

To test our fifth hypothesis, that firm-level transparency is most important following sudden large market downturns, we use a country-month level indicator variable (MKTDOWN_BIG) which is equal to one if, in the prior month, the country's stock market fell by more than one and a half times its average historical standard deviation. To capture the incremental effect of transparency during a 'crisis period' we interact our aggregate transparency variable (TRANS) with the market downturn indicator (MKTDOWN_BIG). 
Following papers such as Stoll (2000), models used in testing H1 through H5 include controls for monthly: market value of equity (SIZE), book to market (BM), return variability (STDRET) and firm-specific returns (FRET). To ensure our results are attributable to the variability of liquidity, as opposed to its level, we include in all models a control for the firm's monthly average level of liquidity (ILLIQ). All market-based control variables are measured as of the beginning of the prior month. Because the turnover measures we use in computing illiquidity reflect only the local market and may be affected by whether a firm also has a foreign listing, we also include indicator variables for whether the stock trades in the U.S., either on an exchange ( $\left.A D R \_E X\right)$ or on the OTC or PORTAL markets $\left(A D R \_N E X\right)$. Similarly, because closely-held shares are typically not available to be traded, we include a control for the proportion of the firm's shares that are closely-held (CLHLD). Finally, to control for differences in business risk, we include controls for the standard deviation of sales (STD_SALES) and the frequency of accounting losses (LOSS_FREQ). All accounting-based control variables are measured as of the prior fiscal yearend date. Calculation of the control variables is described in more detail in the Appendix.

In our main specifications, we include country and year fixed effects. While transparency likely differs across countries, market microstructure and general institutions do as well, so country fixed effects are potentially important. Year fixed effects should mitigate the influence of overall macroeconomic conditions. In addition, we report in the text untabulated regression results including firm fixed effects. While firm fixed effects have the advantage of abstracting from firm-level characteristics that may differ between transparent and opaque firms, they also limit our ability to detect effects associated with our primary accounting variables since changes in auditor and accounting standards are relatively uncommon, and earnings smoothing is computed over multi-year windows and changes slowly.

Our final hypothesis is that each of our liquidity variability and covariability measures is negatively related to Tobin's Q. Following research such as Tobin (1969) and Claessens, Djankov, Fan and Lang (2002), Tobin's Q $(Q)$ is defined as: (book value of assets + (market value of equity - book value of equity))/book value of assets. It is designed to reflect the valuation placed on the assets by the market relative to their book value and inherently incorporates the cost of capital used by the market in discounting future cash flows. In our $Q$ 
regressions, we include the following controls suggested by prior literature [e.g., Claessens et al. (2002)] and further described in the Appendix: LNTOTASS, LEV, CASH, NIEX, IND_Q, AGROWTH, ADR_EX, ADR_NEX, and ILLIQ.

\subsection{Data}

Accounting and market data are from Datastream Advance over the 1996-2008 time period. We require that observations have the necessary financial statement data to calculate our transparency and primary control variables and sufficient market data to calculate the Amihud (2002) price impact of trade measure. We exclude countries with less than 1,000 firm-month observations and limit our sample to the primary exchange in each country to ensure that variation across exchanges within a country is not an issue. Table 1 reports the country representation for our sample, which includes 37 countries representing a wide range of transparency, liquidity and general economic circumstances. To the extent there is clustering, it is in Japan and the U.S., reflecting the relative size of the economies as well as data availability.

Table 2 provides descriptive statistics for our sample firms. The median firm is covered by three analysts. Of the sample firms, 47.4\% have Big-5 auditors, $26.8 \%$ follow an international form of GAAP and 7.5\% trade ADRs, of which 3.3\% are exchange-traded. The average firm has about $30 \%$ concentrated ownership and a book-to-market ratio of 0.63 .

Table 3, Panel A provides correlations for our primary dependent variables. The correlations between the liquidity covariance measures and other liquidity variables are generally very low, suggesting that liquidity covariances are largely independent of our other variables. Among the other variables, the highest correlation is between LIQVOL and LIQSKEW (0.45 Spearman, 0.47 Pearson). As discussed later, results for each of our analyses are robust to including the other variables as controls, suggesting that each variable captures a different underlying construct. Table 3, Panel B shows correlations between our transparency proxies and control variables. 


\section{Empirical Results}

\subsection{Transparency and Liquidity Volatility}

Before turning to the formal empirical analysis, Figure 1 provides an illustration of the timeseries behavior of liquidity volatility. We divide the sample into firms above the sample median transparency (HTRANS) and below the median (LTRANS). To enhance comparability across the transparency partitions, we first orthogonalize $L I Q V O L$ to the control variables from our primary analysis (liquidity, size, book-to-market, return variability, firm return, ownership structure, ADR listing, sales volatility, loss frequency and country fixed effects).

Several points are worth noting, each of which is consistent with our hypotheses. First, liquidity volatility is variable, consistent with the notion that exogenous shocks create variability in liquidity, and those shocks vary over time. Second, the volatility of liquidity is, on average, lower for more transparent stocks. Third, during periods of relative calm, the volatility of liquidity is low and more similar across different levels of transparency. During crisis periods, volatility of liquidity increases, particularly for the more opaque firms. There are five clear spikes on the graph - the Asian Financial Crisis in 1997, the Long-term Capital Management crisis in 1998, September 11, 2001, the bankruptcy of WorldCom and the end of the dot-com boom in 2002, and the beginning of the current financial crisis in 2008. This pattern is consistent with the notion that uncertainty about intrinsic value and, therefore, transparency is less of an issue during periods in which markets are calm and trader capital and funding liquidity are high, but is much more of an issue during crisis periods when trader capital and funding liquidity are limited and economic uncertainty is elevated.

Table 4 reports regression results for the liquidity volatility and transparency analysis. In terms of control variables, liquidity variability tends to be higher for firms that are small, illiquid, unprofitable and closely held, consistent with the notion that it will be assets with relatively greater uncertainty about intrinsic value for which the effects of exogenous shocks will be most pronounced in terms of liquidity variability. All analyses include country and year fixed effects (coefficients not reported), and standard errors that are clustered at the firm level. 
In terms of our primary relations of interest, liquidity is more volatile when transparency is lower as reflected in more evidence of earnings management, use of a small auditor and reliance on local accounting standards, as well as for firms that are followed by fewer analysts and for whom analyst forecasts are less accurate. Including the five transparency variables together, each retains its sign and significance, except for INTGAAP, which is no longer significantly negative. Of course, the transparency variables are unlikely to be independent of each other (e.g., high quality auditors and non-local accounting standards likely affect the ability to manage earnings as well as analyst forecast accuracy and, potentially, analysts willingness to cover the firm). For this reason, and for parsimony going forward, we combine the transparency measures by ranking each variable and summing the ranks to compute an overall transparency measure, TRANS.

Table 4 also reports results including the overall transparency variable. ${ }^{12}$ As expected, TRANS is significantly negatively correlated with liquidity volatility. The incremental explanatory power of transparency for liquidity volatility is highly statistically significant (partial F of 9,326, pvalue $<0.01$ ) and is economically significant as well. Based on the coefficient estimates in Table 4 , holding all else equal, a shift from the $90^{\text {th }}$ to the $10^{\text {th }}$ percentile of TRANS is associated with a $140.1 \%$ increase in liquidity volatility for the median firm.

Repeating the analysis with firm fixed effects, results (untabulated) are consistent. Each of the transparency variables retain their signs and four of the five transparency components remain statistically significant (the exception is BIG5 which has a p-value of 0.15 , likely reflecting limited within-firm variation) as does aggregate TRANS. These results are reassuring because they help mitigate the concern that our primary results simply capture differences across firms.

\subsection{Transparency and Extreme Illiquidity Events}

In Hypothesis 2, we predict that greater opacity will be associated with more frequent extreme illiquidity events, reflecting the fragility of liquidity for opaque stocks. As noted earlier, we

\footnotetext{
${ }^{12}$ Weightings of TRANS based on a factor analysis yield similar results. In addition, any of the individual transparency components can be excluded from the construction of the TRANS variable with consistent results.
} 
consider two approaches: LIQSKEW, the skewness of illiquidity, and $L B H$, an indicator for cases in which it is more than 50 times as expensive to transact as the median for that country-year.

Table 5 reports results relating transparency to liquidity skewness and liquidity black holes. In terms of control variables, for both specifications, extreme illiquidity tends to be more pronounced for smaller firms with lower liquidity and less variable sales. In terms of our primary variable of interest, TRANS is negatively correlated with both LIQSKEW and $L B H$, suggesting that, controlling for other factors, extreme illiquidity events are less common for more transparent firms. In addition, results for each variable (LIQSKEW and $L B H$ ) are robust to controlling for the other, suggesting that the two variables capture different underlying economic constructs. The partial F-statistics for TRANS in the two regressions are 280 and 924 (p-values < 0.01 ) for $L I Q S K E W$ and $L B H$, respectively, indicating significant incremental explanatory power. In terms of economic significance, the magnitude of the effect of TRANS is probably best illustrated with the $\mathrm{LBH}$ variable, since the economic interpretation of that variable is more intuitive. Moving from the $90^{\text {th }}$ to the $10^{\text {th }}$ percentile of transparency, there is a $46.3 \%$ increase in the frequency of extreme illiquidity events, suggesting that the magnitude of the transparency effect is substantial.

Results (untabulated) for extreme illiquidity events are consistent when including firm fixed effects. The coefficient on TRANS remains strongly negatively associated with both LIQSKEW and $L B H$, mitigating concerns about omitted correlated variable bias. Overall, the results strongly suggest that more transparent firms are less likely to experience extreme illiquidity events.

\subsection{Transparency and Liquidity Commonality}

Our earlier discussion suggests transparency has the potential to affect not only the variability of firm-level liquidity, but also its covariability with market liquidity and market returns. Table 6 presents results for the liquidity covariability analysis. In terms of controls, across both specifications, liquidity covariability tends to be higher for less liquid and smaller stocks with less variable returns that do not trade on U.S. exchanges and that experience more frequent losses. Other control variables tend to be insignificant or differ based on the specification. In 
terms of our primary variables of interest, as predicted, $\operatorname{COM}(F L, M L)$ is significantly lower when firms are more transparent. In other words, more transparent firms are less likely to have substantial reductions in liquidity at the same time that liquidity is low for other firms in the market. This is likely to be particularly important to investors because they value liquidity in a given stock more highly when other stocks in their portfolio have become illiquid. ${ }^{13}$ Similar conclusions obtain for $\operatorname{COM}(F L, M R$,) in Table 6 Column (2). Again, the coefficient on TRANS is significantly negative, suggesting that more transparent firms are less likely to experience illiquidity at times when investors are more likely to want to sell shares (during market downturns when speculator capital tends to be low).

Overall, our results suggest liquidity is less cyclical for more transparent firms, both relative to market liquidity and market returns. There is significant incremental explanatory power (partial F of 65 and 32, p-values $<0.01$ ) and, in terms of economic significance, the coefficient estimates imply that moving from the $90^{\text {th }}$ to the $10^{\text {th }}$ percentile of transparency is associated with a $5.3 \%$ increase in the covariance of firm-level liquidity with market liquidity and a 3.5\% increase in the covariance of firm-level liquidity with market returns. As discussed later, the magnitude of the effect becomes substantially larger during crises.

Coefficients remain negative in both specifications using firm fixed effects, but are no longer statistically significant, potentially reflecting the limited variation in the transparency variable. However, looking ahead to the crisis period analysis, the TRANS coefficient is significantly negative for both of the liquidity covariance measures during both large and small crises with firm fixed effects, confirming that transparency is particularly important during crisis periods.

\subsection{Robustness}

Our results are robust to a wide range of alternative specifications. First, we investigate alternate measures of illiquidity. We focus on measures of price impact because the theoretical framework that motivates our study uses the magnitude of the discount associated with transacting as a

\footnotetext{
${ }^{13}$ The modest $\mathrm{R}^{2}$ here reflects, at least in part, the fact that our dependent variables are measured monthly while some of our independent variables are measured annually. Prior research [e.g., Hameed et al. (2010)] does not report

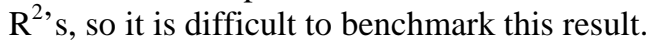


proxy for liquidity. This notion of liquidity incorporates both the bid-ask spread and depth. Thus, to conduct our analyses, we need a variable that can be measured on a daily basis and captures market depth. Goyenko, Holden and Trzcinka (2009) suggests several alternative measures of price impact. The measure best suited for our analysis is the spread impact measure, which is based on the notion that liquid stocks are those for which a substantial volume can be transacted without affecting bid-ask spreads. In Table 7, Panel A, we replicate our primary analyses using the bid-ask spread impact measure, BAVOL, calculated as the firm's daily bid-ask spread, in percentage terms, scaled by daily U.S. dollar trading volume. ${ }^{14}$ The derivative liquidity uncertainty measures are then calculated as described in Section 4.1. Results are consistent with those in our prior analyses. Transparency remains significantly negatively associated with all five of our liquidity uncertainty measures calculated using the bid-ask spread impact measure.

Second, we consider an alternate construction of the Amihud measure including zero return days. Our primary approach excludes zero return days for consistency with prior literature [e.g., Karolyi et al. (2010) and Daske et al. (2008)]. A problem with using zero return days in the Amihud measure is that the numerator is zero and, therefore, a day with a thousand dollars traded and zero returns is treated equivalently to a day with a million dollars traded and zero returns, even though those are quite different from a liquidity perspective. To circumvent this issue, we replicate the analysis substituting a $0.01 \%$ return on zero return days with positive volume so that trading volume enters into the calculation. All results (untabulated) are robust to this modification. Similarly, results are robust to assigning an illiquidity of $0 \%$ to zero return days.

Third, because the Amihud measure is naturally skewed, we conduct several additional analyses to ensure distributional properties of the Amihud measure, or any of our other derivative dependent variables, do not unduly influence our results. ${ }^{15}$ We repeat our analyses using a version of the Amihud measure, DPI, that deflates dollar trading volume $\left(P^{*} V O\right.$ in the denominator) by market value of equity. This alternative measure can be interpreted as the percent of shares outstanding an investor can trade without affecting share price and is less

\footnotetext{
${ }^{14}$ Another alternative measure in Goyenko et al. (2009) is the Amivest measure based on the ratio of trading volume to the absolute value of returns. Results are also robust to this measure of price impact.

${ }^{15}$ It is important to note that, in all of our primary analyses, we use a logarithmic version of each of our dependent variables (except for LIQSKEW) which significantly reduces skewness and the influence of outliers. For example, the mean and median of our liquidity volatility variable are virtually identical (-3.97 and -3.99 respectively).
} 
skewed than the non-deflated version of DPI. Inferences based on this alternative measure are identical to those in the prior analyses. To further abstract from distributional assumptions, we repeat our analyses using percentile rank regressions. Across all of our liquidity uncertainty measures, except LIQSKEW which by definition is not well suited for rank regression analysis, we continue to find a significant negative relation with transparency.

Fourth, we repeat our liquidity commonality analyses using the sum of the $\beta_{1}, \beta_{2}$ and $\beta_{3}$ coefficients, instead of the $R^{2}$, from Equations (2) and (3) to construct $C O M(F L, M L)$ and $C O M(F L, M R)$, respectively. Although our primary approach is consistent with the prior literature [e.g., Hameed et al. (2010)], a potential concern with using the $R^{2}$ is that our measures of commonality are constrained to be positive. Because we cannot use a log transformation, we truncate the beta coefficient-based $\operatorname{COM}(F L, M L)$ and $C O M(F L, M R)$ measures at the $5 \%$ level to control for extreme observations. Results using the sum of $\beta_{1}, \beta_{2}$ and $\beta_{3}$ are consistent with those reported in Table 6.

Fifth, because they represent such a significant portion of our sample, we repeat our analyses limiting Japanese and U.S. firms to $10 \%$ of our sample, and eliminating Japanese and U.S. firms entirely. Results (untabulated) are robust to limiting or excluding Japanese and U.S. firms. Moreover, our inferences are robust to limiting or excluding any other country in our sample. In fact, repeating our analysis within each of the 37 countries in our sample, the coefficient estimate on transparency is negative in 34 countries (32 significantly) for liquidity volatility, 26 countries (22 significantly) for liquidity skewness, 28 countries (20 significantly) for liquidity black holes, 23 countries (16 significantly) for the correlation between firm-level liquidity and market liquidity and 25 countries (14 significantly) for the correlation between firm-level liquidity and market returns, confirming the consistency of our findings across a wide range of countries. ${ }^{16}$

\footnotetext{
${ }^{16}$ We also repeat our analyses using only firms located in the U.S. for comparability with prior U.S.-based research. U.S. firms tend to be relatively homogenous in terms of transparency and liquidity, and exhibit very limited variability on several of our transparency variables (e.g., accounting standards, large auditor and earnings smoothing). Overall, conclusions are consistent with those reported earlier, with TRANS significantly negatively related to each of our primary independent variables of interest.
} 
Sixth, we repeat our analyses using a changes specification. While the firm fixed effects analysis controls for static firm-level effects, an analysis based on first differences explicitly focuses on time series covariation between the variables. Because our accounting transparency variables are measured primarily using annual data, we first annualize the dependent and independent variables and then compute changes, resulting in a substantial decrease in sample size. As with our primary analysis, transparency is lagged relative to the liquidity variables. Results of these regressions are reported in Table 7, Panel B. The coefficient on TRANS is negative and significant, at least at the $10 \%$ level, in all five specifications, providing further comfort that our results are not driven by omitted firm-level variables. ${ }^{17}$

Seventh, we repeat each of the analyses including the other four liquidity uncertainty variables as controls to ensure that our results are incremental across variables. Results are robust to inclusion of the other variables, either individually or as a group, indicating that each of our dependent variables of interest is separable from the other variables. Results are also robust to controlling for the correlation between firm-level returns and market liquidity discussed in Pastor and Stambaugh (2003) and Ng (2010).

Eighth, we consider several other fixed effects and methods of standard error clustering. Our primary analyses include country and year fixed effects and standard errors clustered at the firm level. However, liquidity might be correlated with calendar-month or with a firm's industry. Results are robust to inclusion of calendar-month and industry fixed effects. Results are also consistent when including combinations of the various fixed effects, including, country-year and industry-year. Inferences are robust to also clustering standard errors by country and industry.

Ninth, we repeat our analyses including a firm-level control for institutional holdings. The concern here is that institutions might be providing liquidity while also influencing firm-level transparency. Our control for institutional holdings is constructed from international mutual fund ownership data from Thomson Reuters and is defined as the total number of shares owned by mutual funds divided by the total number of shares outstanding. Although the inclusion of the

\footnotetext{
${ }^{17}$ Some of the time series variation in transparency in the changes analysis arises from changes in transparency rankings when other firms adjust their transparency. To ensure that does not drive our results, we estimated transparency rankings for the entire pooled sample period, rather than annually, with similar results.
} 
institutional ownership control variable decreases our sample size by approximately $40 \%$, we continue to find results consistent with those reported for our primary analyses.

Tenth, we consider an alternate sample selection technique based on propensity score matching to ensure that our results are not capturing differences in business risk, as opposed to transparency, that affect liquidity. We divide the sample into two groups based on country-level median transparency and then estimate the propensity to be in the high- versus low-transparency group based on a variety of proxies for business risk, including size, leverage, book to market, sales volatility, loss frequency, operating cycle, sales growth, operating leverage, average cash flows and industry membership. We then exclude the $25 \%$ of high transparency firms with the highest propensity scores and the $25 \%$ of low transparency firms with the lowest propensity scores so that we are left with the $50 \%$ of the sample that is most similar in terms of the business risk characteristics associated with transparency. Results from this alternate sample are very similar to those reported in our primary analyses.

Finally, to further address endogeneity concerns, we model transparency and liquidity variability in a two-stage least squares framework. Following prior research such as Roulstone (2003) and $\mathrm{Yu}$ (2008), a primary concern is that analyst following may be endogenously determined based on investor demand for information. ${ }^{18}$ We follow Roulstone (2003) and Yu (2008), in modeling determinants of transparency. In our two-stage least squares analysis (untabulated), we estimate a first-stage model which features transparency (TRANS) as a function of two sets of variables: potentially endogenous variables (ILLIQ, SIZE, BM, STDRET, CLHLD, ADR_EX, and $\left.A D R \_N E X\right)$, and variables suggested by research such as Lang and Lundholm (1996), Roulstone (2003), and Yu (2008) as instruments for transparency (return-earnings correlation and asset growth, computed over the prior three- to five-year window, and one-year lagged return on assets). Our second-stage (structural) models use the same independent variables as Tables 4-6, with each of our five liquidity uncertainty measures, as the dependent variables. Instruments in

\footnotetext{
${ }^{18}$ The argument with respect to analyst following could be in either direction. First, analysts may be attracted to firms with highly volatile liquidity because the liquidity changes tend to move prices away from fundamentals and, thus, provide opportunities for profitable trade, which would bias against our findings. Alternatively, analysts may avoid firms where future liquidity is expected to be volatile because investors prefer not to invest in those stocks, which could bias in favor of our results. It is more difficult to make an analogous argument for our other measures of transparency because that would imply that firms, faced with the possibility of volatile liquidity would reduce transparency by choosing lower quality auditors and accounting standards, and increasing earnings management.
} 
the first stage are significantly related to transparency and the Cragg-Donald statistic indicates that we do not suffer from weak instruments [Stock and Yogo (2005)]. Results from the structural models are consistent with those reported earlier in that transparency remains significantly negatively correlated with each of our liquidity uncertainty measures.

\subsection{Institutional Analysis}

We have, thus far, avoided comparing results across countries because of potential differences in market microstructure and design features across exchanges. Market microstructure is particularly a concern for our measures because they incorporate volume, which may be calculated differently across exchanges [Lesmond (2005)]. Nonetheless, implications for our measures of transparency likely vary based on country-level institutions. Prior literature suggests there are potentially two countervailing effects depending on whether our transparency measures are more likely complements or substitutes for the more general institutional environment.

First, stronger overall investor protection and enforcement likely increase the impact of the adoption of high quality accounting standards and the benefits of hiring high quality auditors. Prior research provides evidence that the use of international accounting standards and high quality auditors is most beneficial in environments in which there is substantial local oversight and litigation exposure [Daske et al. (2009) and Hope, Kang, Thomas and Yoo (2009)]. As a result, we expect the presence of 'Big-5' auditors and international accounting standards to be a complement to stronger local institutions in terms of their effect on overall firm transparency.

On the other hand, research such as Lang et al. (2004) suggests that analysts are more important when local institutions are weak because weak regulatory environments create an enhanced role for private information acquisition. As a consequence, we expect analyst following and forecast accuracy to be more strongly associated with liquidity uncertainty when local institutions are relatively weak. Similarly, to the extent that earnings management reduces the information content of reported earnings, we expect discretionary smoothing to be more of an issue in environments with low overall levels of transparency. 
We follow the classification in Leuz (2010) in splitting countries into clusters using regulatory, enforcement and reporting practice variables. Countries classified as having a strong institutional infrastructure are in Cluster 1, while those with progressively weaker institutions are placed into Clusters 2 and 3. Our institutional infrastructure indicator (WEAK) takes a value of one if a country is in Regulatory Cluster 2 or $3 .{ }^{19}$ In addition, we split our transparency variables into those we expect to be complements to local institutions (INTGAAP and BIG5, aggregated into COMP_TRANS) and those we expect to be substitutes (ANALYST, ACCURACY and DIS_SMTHC, aggregated into SUB_TRANS).

Results for liquidity volatility, presented in Table 8, are consistent with expectations. Specifically, COMP_TRANS*WEAK is significantly positive while SUB_TRANS*WEAK is significantly negative, suggesting that weak country-level institutions mitigate the effectiveness of international accounting standards and 'Big-5' auditors, but reinforce the importance of analyst following, forecast accuracy and discretionary smoothing. ${ }^{20}$ Table 8 also reports results for incidence of extreme illiquidity events, liquidity skewness and liquidity black holes. Results are consistent with those for liquidity volatility. The interaction between COMP_TRANS and WEAK is positive and the interaction between SUB_TRANS and WEAK is negative. ${ }^{21}$ Similar results hold for $\operatorname{COM}(F L, M L)$ and $\operatorname{COM}(F L, M R)$, which are both positively associated with COMP_TRANS*WEAK and negatively associated with SUB_TRANS*WEAK. Subject to the caveat that our liquidity measures may not be entirely comparable due to differences in market microstructure across countries, the results suggest that the effects of our transparency indicators vary predictably across local institutional environments.

\footnotetext{
${ }^{19}$ We combine Clusters 2 and 3 because we have very few observations in Cluster 3, and both clusters represent "insider" economies. Results are consistent if we exclude Cluster 3 countries. Further, because it comprises a substantial portion of our sample, following prior literature [e.g., Allen, Qian and Qian (2005)] we include China in the weak institutional group although cluster data are not available for China in Leuz (2010). Results are consistent if we exclude China from the analysis.

${ }^{20}$ Comparing the WEAK interaction coefficients for the transparency subcomponents (not tabulated for parsimony), each is of the predicted sign, and ANALYST, BIG5 and INTGAAP are statistically significant.

${ }^{21}$ For parsimony, in our primary analysis only the transparency indicators are interacted with the WEAK indicator. Results are very similar if we also allow the control variables to vary based on the institutional environment.
} 


\subsection{Transparency, Liquidity Uncertainty and Crises}

To this point, we have implicitly assumed that the relation between transparency and liquidity variability and covariability is invariant to the stage in the economic cycle. However, as argued earlier, transparency should be especially important following sharp market downturns when speculator capital is low, limiting their ability to take positions in capital intensive stocks, and overall uncertainty is high. As discussed earlier, Figure 1 suggests that liquidity volatility increases substantially during crisis periods, especially for less transparent firms.

Table 9, Column (1), presents results for the liquidity volatility analysis with an interaction term for large market downturns. Several points are worth noting. First, the indicator variable for large market downturns is positive and strongly significant suggesting that, consistent with Figure 1, large downturns are associated with greater liquidity volatility. Second, the coefficient on transparency remains strongly negative, confirming that transparency is associated with reduced liquidity volatility on average. Third, and most importantly, the coefficient on the interaction between transparency and the market downturn indicator is negative and statistically significant, suggesting that transparency is substantially more important during crises. ${ }^{22}$

The fact that the effects are strongest for crisis periods provides some comfort that our overall results do not reflect omitted correlated variables. For example, suppose that the documented association between liquidity volatility and transparency was driven by an omitted variable. For that to explain our results, the omitted variable would need to be both correlated with transparency and the strength of that relation would need to change substantially during market downturns. While that is possible, it is more difficult to envision a variable with those features. Similarly, the increased importance of transparency during crisis periods reduces the likelihood that our results reflect reverse causality because the market downturn shock is exogenous to the firm and liquidity volatility is measured over a month-long window, while the transparency measure is computed annually. It is unlikely that the stronger relation between liquidity volatility

\footnotetext{
${ }^{22}$ Additional, untabulated, analyses indicate that the coefficient on our transparency variable spikes during a crisis before returning to near average levels six months afterward, indicating that transparency maintains a heightened importance for several months following a crisis. For parsimony, only the transparency indicators are interacted with the crisis indicators. Results are very similar if we allow all coefficients to vary by the crisis indicator.
} 
and transparency during crisis months is driven by decreases in transparency for firms that suddenly experience increased liquidity volatility. Also, the fact that the transparency measure is computed prior to the beginning of the crisis period makes it difficult to imagine a role for reverse causality.

Further, we predict that the more severe the crisis, the greater the mitigating effect of transparency. In Table 9, Column (2), we divide our crisis variable into two pieces, smaller downturns (monthly downturns between 1.5 and 2.0 standard deviations) and larger downturns (monthly downturns of more than 2.0 standard deviations). Based on the descriptive evidence from Tables 1 and 2, our smaller downturns involve a monthly negative stock return of $10.5 \%$ on average, ranging from $6 \%$ for the United Kingdom to over $20 \%$ for Turkey, while our larger downturns average $14 \%$, ranging from $8 \%$ for the United Kingdom to $30 \%$ for Turkey. ${ }^{23}$

Results, reported in Table 9, Column (2), indicate that, as predicted, liquidity volatility increases to a greater extent the more extreme is the downturn. More importantly, the coefficient on the large downturn indicator is significantly larger than the smaller downturn indicator, indicating that transparency is most important during large downturns. In terms of economic significance, the implied effect of a shift from the $90^{\text {th }}$ to $10^{\text {th }}$ percentile of TRANS would be a $218.4 \%$ increase in liquidity volatility in a small crisis and a $359.2 \%$ increase in a larger crisis. Very similar conclusions hold for the analyses with firm fixed effects (untabulated), mitigating concerns about omitted firm characteristics.

Similar conclusions obtain for extreme illiquidity events, reported in Table 9, Columns (3) and (5). Large down markets increase the skewness of liquidity and frequency of extreme illiquidity events. Further, transparency remains significantly negative suggesting that extreme illiquidity events are less of an issue for more transparent firms. Most importantly, the interaction between MKTDOWN_BIG and both LIQSKEW and $L B H$ is significantly negative, suggesting that

\footnotetext{
${ }^{23}$ We define our crisis events relative to country averages because a given size downturn is less likely to be viewed as a crisis for a country in which returns are typically more volatile. Results are very similar if we impose the same criterion in terms of return magnitude for downturns across countries.
} 
transparency is particularly important to extreme illiquidity events in crisis periods. ${ }^{24}$ Further, splitting by the size of the down market in Table 9, Columns (4) and (6), we find TRANS is significantly more negatively associated with extreme illiquidity events in larger market downturns. The coefficient estimates from the $L B H$ analysis imply that a shift from the $90^{\text {th }}$ to the $10^{\text {th }}$ percentile in TRANS would be associated with an $85.3 \%$ increase in liquidity black holes in a smaller crisis and a $236.8 \%$ increase in a larger crisis. Results are again consistent for firm fixed effects (untabulated) for both measures of extreme illiquidity events.

In Table 9, Columns (7) through (10), we present results for the covariability of firm-level liquidity with market liquidity and with market returns. Conclusions are consistent with expectations and with results for liquidity volatility and extreme illiquidity events. When the market drops, liquidity covariability with both market liquidity and market returns increases significantly. Second, as before, transparency is associated with lower levels of both types of liquidity covariability. Third, and most important, the effect of large market downturns on both types of liquidity covariance is substantially mitigated in the presence of greater transparency. The TRANS*MKTDOWN_BIG coefficient suggests transparency is more than four times as important in mitigating the covariability between firm-level transparency and market returns during downturns. Focusing on large downturns, the effect of transparency is five and a half times greater than during non-crisis periods. Turning to the covariability of firm-level liquidity with market returns, the effect of transparency is more than three times as large during crisis periods in general and more than four times as important during large crises.

Results are consistent with firm fixed effects (untabulated). Both measures of covariance increase during crises, but significantly less so for firms that are more transparent. Further, the effects of a crisis on the covariation of firm-level liquidity with market liquidity, and the mitigating effect of transparency, are significantly more pronounced for larger crises. The coefficient estimates from the $\operatorname{COM}(F L, M L)$ regressions imply that a shift from the $90^{\text {th }}$ to the $10^{\text {th }}$ percentile in TRANS would be associated with an $19.6 \%$ increase in covariability of firm-

\footnotetext{
${ }^{24}$ In interpreting the coefficient estimates on the interactions between crises and transparency, it is important to recognize that MKTDOWN_BIG is an indicator variable while TRANS is a continuous variable with a mean of 0.50 . As a result, the magnitude of the coefficient on MKTDOWN_BIG*TRANS is directly comparable to the coefficient on TRANS but not to the coefficient on MKTDOWN_BIG.
} 
level liquidity with market liquidity in a smaller crisis and a $43.5 \%$ increase in a larger crisis, while the coefficient estimates from the $\operatorname{COM}(F L, M R)$ regressions imply that a similar shift from the $90^{\text {th }}$ to the $10^{\text {th }}$ percentile would be associated with a $7.5 \%$ increase in covariability of firmlevel liquidity with market returns in a smaller crisis and a $19.1 \%$ increase in a larger crisis

\subsection{Other Analyses}

To provide further support for the previously documented relation between transparency and liquidity uncertainty during crises, we supplement our primary analysis in several ways. First, a potential concern is that, because they are measured with a lag, our transparency variables do not capture transparency during a crisis month. Given that we use data from annual financial reports, we cannot construct monthly financial statement variables. However, the $\mathrm{I} / \mathrm{B} / \mathrm{E} / \mathrm{S}$ summary file is updated more frequently, so we can re-estimate our analyses using a measure of transparency based on analyst following and accuracy during the crisis month. Results (untabulated) suggest that greater levels of transparency are associated with lower values of each of our liquidity variability and covariability measures, and that the effect of this monthly transparency variable is significantly more pronounced during crisis periods for each liquidity measure. Including the monthly analyst transparency indicator along with our annual transparency measure, the monthly analyst variable is incrementally significant, consistent with the notion that transparency during the crisis period is particularly important to liquidity variability and covariability.

Second we investigate whether the firms we identify as having high levels of transparency actually disclose more during crisis periods. We expect a mediating effect if the firm has a high level of transparency during a crisis, regardless of whether that occurs by virtue of high transparency levels in general or changes during the crisis. However, transparent firms might also be more likely to increase transparency during crises in response to increased investor demand for information. While it is difficult to directly examine changes in disclosure that occur during a crisis, prior research [e.g., Lang and Lundholm (1993)] suggests one way to infer such changes is by examining the frequency of analyst forecast updates. If more information is reaching the market, either through firm-provided disclosure or private information acquisition, forecast updates should be more frequent. We examine the number of forecast revisions per 
analyst during crisis months across high and low transparency firms (based on the sample median) controlling for the other variables used in our primary analyses. Results (untabulated) indicate that firms we identify as more transparent have more forecast revisions per analyst during crisis months, suggesting more new information is available for these firms during crises.

Third, we repeat our analyses using a definition of crises based on significant increases in market-wide illiquidity rather than large market downturns. Although defining crises based on significant market downturns is most consistent with the prior theoretical and empirical literature which links liquidity uncertainty to speculator funding constraints, given that our analysis focuses on liquidity it is also interesting to consider whether the importance of transparency in mitigating liquidity uncertainty increases during market liquidity crises. Similar to our calculation of MKTDOWN_BIG, our measure of market liquidity crises is a country-month level indicator variable equal to one if the country's average level of illiquidity is more than one and a half times its historical standard deviation. Results using this alternative definition of crises are consistent with those reported in our primary analysis in Table 9. We continue to find that the association between TRANS and each of our five measures of liquidity uncertainty is significantly more negative during months of extreme country-level illiquidity. In addition, we replicate our analysis using contemporaneous (as opposed to lagged) large downturns. Our primary analysis uses lagged downturns to capture situations in which speculator capital has been depleted. Results are consistent using contemporaneous downturns.

Fourth, we replicate our crisis period analysis substituting a measure of firm-specific monthly CAPM beta for our measures of liquidity covariability. The CAPM disaggregation in Acharya and Pedersen (2005), suggests that, because downturns decrease speculator capital, they can increase the price pressure associated with trading and increase a firm's CAPM beta. Untabulated results are consistent with those in Table $9 .{ }^{25}$ Specifically, we find there is a significant increase in CAPM beta during downturns, but the increase in beta is significantly smaller for more transparent firms. Coupled with our earlier results, this finding suggests that,

\footnotetext{
${ }^{25}$ For consistency with prior covariance results in the paper, we estimate a firm's beta relative to its own-country return (although results are consistent if we estimate beta based on world-wide returns). Because we do not address issues such as market integration, the role of information in a CAPM world or alternate approaches to computing beta, our results are only intended to be descriptive
} 
during downturns, firms' returns covary more with market returns because of the increased price pressure associated with trading and that transparency substantially mitigates this effect.

Finally, we investigate whether our results appear to be driven by mechanisms suggested by theoretical research. Papers such as BP (2009) assume that funding constraints faced by speculators are the impetus for variability and covariability in liquidity. Unfortunately, we do not directly observe funding constraints, so our evidence is necessarily circumstantial. However, there are two related implications that we can examine indirectly. First, BP (2009) predicts that low volatility securities will be less sensitive to specialists funding constraints because they are less risky and thus less capital intensive. ${ }^{26}$ If speculator funding constraints are at work, increases in liquidity volatility, and the effect of transparency in mitigating these increases during crisis periods, should be most pronounced for high volatility stocks. Splitting our sample into high and low volatility subgroups based on the country-level medians, we find, consistent with the predicted effects of funding constraints, that the effect of a crisis on liquidity volatility is significantly larger for stocks from countries with high levels of return volatility and that the mitigating effect of transparency is significantly more pronounced for high volatility stocks.

Second, we compare results across subgroups based on country-specific levels of institutional ownership. BP (2009) suggests that institutional investors (e.g., hedge funds, commercial banks and investment banks) play the role of speculators in their model. If so, the effects of crises on liquidity volatility, and the mitigating effect of transparency, should be most pronounced in environments with higher levels of institutional ownership. Dividing our sample by country-level institutional ownership, based on the data in Ferreira and Matos (2008), results are consistent with predictions. We find the effect of crises on liquidity volatility is most pronounced for firms located in country's with high levels of institutional ownership (based on the sample median). Moreover, the mitigating effect of transparency is more pronounced in these settings as well. While these results are indirect, they provide evidence consistent with the notion that funding constraints on institutional investors are important determinants of liquidity uncertainty.

${ }^{26}$ Comerton-Forde, Hendershott, Jones, Moulton and Seasholes (2010) provides supporting evidence in a U.S. setting, showing market makers funding (and shocks thereto) is less associated with liquidity for low volatility stocks. 


\subsection{Liquidity Variation, Covariation and Valuation}

In our final set of analyses, we examine the relation between liquidity variability and covariability and Tobin's Q. While the notion that investors prefer stocks with more predictable liquidity follows theoretically and intuitively, there is little direct evidence these factors matter for valuation. Table 10 provides evidence on the relation between $Q$ and our liquidity uncertainty measures, controlling for variables suggested by the prior literature [e.g., Claessens et al. (2002)] along with country, industry and year fixed effects. ${ }^{27}$ All right-hand side variables in this analysis are measured over the same year as $Q$ (although results are robust to using lagged variables). Results for the control variables are consistent with expectations. Valuations are higher for firms that are smaller, have more cash, are more profitable, trade ADR's, are from industries with high Q's and are more liquid. ${ }^{28}$ Most importantly, each of our liquidity variability and covariability measures is separately and incrementally negatively correlated with firm value, suggesting that investors are willing to pay more for firms that have lower liquidity variability, lower liquidity skewness, fewer instances of extreme illiquidity, lower covariability with market liquidity and lower covariability with market returns. ${ }^{29}$ Results (untabulated) are robust to controlling for firm fixed effects in that each of the five measures of liquidity uncertainty remains negatively and significantly associated with Tobin's Q, both individually and incrementally.

In order to relate these findings back to our earlier analyses, we examine whether liquidity uncertainty is an important channel through which transparency effects valuation. Prior research [e.g., Lang et al. (2010)] suggests that the average level of liquidity is an important channel through which transparency affects firm value. We investigate whether liquidity uncertainty also

\footnotetext{
${ }^{27}$ A potential concern with our liquidity variability and covariability measures is that they are correlated with market value of equity, which is a component of Tobin's Q. To ensure that relation is not driving our results, we repeat the analysis with market value of equity as a control, with very similar results.

${ }^{28}$ Contrary to Doidge, Karolyi and Stulz (2004), the coefficients on exchange-traded and non-exchange-traded ADRs are not significantly different in our Tobin's Q analysis, although the coefficient on $A D R \_E X$ is larger as expected. This difference could reflect the fact that we have a different sample period and composition or be related to recent evidence that the valuation benefit of exchange-traded ADRs may be only temporary or declining in recent years [e.g., Sarkissian and Schill (2009) and Hostak, Karaoglu, Lys and Yang (2009)].

${ }_{29}$ Results are robust to including our transparency measures in the regression, suggesting that transparency matters to valuation incrementally to its effect on our liquidity variables. This is consistent with the notion that transparency could, for example, also limit expropriation of assets or increase managerial efficiency.
} 
serves as such a channel and how it compares to average liquidity in terms of importance using a mediation analysis, which is conducted by examining the effect on the TRANS coefficient in the Tobin's Q regression of including the level of liquidity and our measures of liquidity uncertainty.

In the mediation analysis, we find that transparency is significantly positively associated with firm value. Moreover, the inclusion of both the level of liquidity as well as each of our measures of liquidity uncertainty in the $Q$ regressions significantly mediates the relation between transparency and firm value, suggesting that each is a path through which transparency affects firm value. Interestingly, the effect of transparency on valuation through our liquidity uncertainty measures is more than twice as large as the effect through the average level of liquidity. In particular, the overall mediating effect of transparency on Tobin's Q associated with an increase in transparency from the $10^{\text {th }}$ to $90^{\text {th }}$ percentile is 0.096 of which 0.065 is from the effect of transparency on liquidity uncertainty and 0.031 is from average liquidity. While this approach is admittedly crude, it suggests that the effect of transparency through liquidity uncertainty may be at least as important as the effect through the level of liquidity. ${ }^{30}$

\section{Conclusion}

Prior research has typically focused on transparency as a determinant of the average level of liquidity. While average liquidity is clearly important, the variability and covariability of liquidity are also relevant because what ultimately matters to an investor is a stock's liquidity at the time they choose to transact. The recent financial crisis provides a vivid illustration of the importance of liquidity variability and covariability during large market downturns. To the extent that uncertainty about intrinsic firm value increases the sensitivity of liquidity to economic shocks, transparency has the potential to reduce liquidity variability and covariability.

Our results suggest a strong relation between transparency and liquidity variance and covariance, consistent with both intuition and theoretical research. Moreover, our results suggest a 'flight to quality' in liquidity during which more transparent stocks are less sensitive to liquidity shocks in

\footnotetext{
${ }^{30}$ Given that Tobin's Q is based on total firm value, the effects we document reflect the benefits of transparency net of any associated costs rather than the gross benefits of transparency.
} 
general and particularly to the liquidity uncertainty that accompanies crisis periods. In addition, we find that the effects of transparency vary predictably across country-level institutional environments, and provide evidence that our results are driven, at least in part, by the effects of funding constraints on institutional investors. Further, we find that each of our liquidity uncertainty measures is negatively correlated with valuation as measured by Tobin's Q. These results are robust to a wide range of sensitivity analyses. While it is dangerous to draw strong causal implications, taken at face value our results suggest that liquidity variability and covariability are important channels through which transparency affects firm value.

Of course, our conclusions are subject to caveats. Most importantly, they do not imply causality. Several features of our empirical design and robustness tests suggest that the primary relations we document are not simply due to endogeneity. Further, it seems unlikely that our findings suffer from reverse causality because we measure transparency prior to the calculation of our liquidity uncertainty variables. Moreover, the fact that the association between transparency and liquidity uncertainty increases during crises reduces the set of alternative explanations for our results. Also, the fact that results are robust to a wide range of sensitivity tests including controls for simultaneity reduces the likelihood of spurious inference. Finally, our empirical results are consistent with the intuition underlying prior analytical research, which reduces the likelihood that they are spurious. That being said, causal conclusions should still be drawn with caution.

Overall, we believe our results represent an important first step in understanding the relation between transparency and liquidity variability and covariability. Our findings are particularly timely in light of the concerns about liquidity generated by the recent economic crisis. Given that money managers and investors view liquidity variability and covariability as major concerns, our results are potentially useful in offering a deeper understanding of the role of transparency. 


\section{REFERENCES}

Acharya, V., Pedersen, L., 2005. Asset pricing with liquidity risk. Journal of Financial Economics 77, 375-410.

Allen, F., Qian, J., Qian, M., 2005. Law, finance and economic growth in China. Journal of Financial Economics 77, 57-116.

Amihud, Y., 2002. Illiquidity and stock returns: Cross-section and time-series effects. Journal of Financial Markets 5, 31-56.

Amihud, Y., Mendelson, H., Pedersen, L., 2005. Liquidity and asset prices. Foundations and Trends in Finance 1, 269-364.

Ang, A., Chen, J., 2002. Asymmetric correlations of equity portfolios. Journal of Financial Economics 63, 443-494.

Ball, R. 2001. Infrastructure requirements for an economically efficient system of public financial reporting and disclosure. Brookings-Wharton Papers on Financial Services, 127169.

Barth, M., Landsman, W., Lang M., 2008. International accounting standards and accounting quality. Journal of Accounting Research 46, 467-498.

Bradshaw, M., Miller, G., 2008. Will harmonizing accounting standards really harmonize accounting? Evidence from non-US Firms adopting US GAAP. Journal of Accounting Auditing and Finance 23, 233-263.

Brockman, P., Chung, D., 2002. Commonality in liquidity: Evidence from an order-driven market structure. Journal of Financial Research 25, 521-539.

Brunnermeier, M., Pedersen, L., 2009. Market liquidity and funding liquidity. Review of Financial Studies 22, 2201-2238.

Claessens, S., Djankov, S., Fan, J., Lang, L., 2002. Disentangling the incentive and entrenchment effects of large shareholdings. The Journal of Finance 57, 2741-2771.

Comerton-Forde, C., Hendershott, T., Jones, C., Moulton, P., Seasholes, M., 2010. Time variation in liquidity: The role of market-maker inventories and revenues. The Journal of Finance 65, 295-331.

Daske, H., Hail, L., Leuz, C., Verdi, R., 2008. Mandatory IFRS reporting around the world: Early evidence on the economic consequences. Journal of Accounting Research 46, 10851142. 
Daske, H., Hail, L., Leuz, C., Verdi, R., 2009. Adopting a label: Heterogeneity in the economic consequences of IFRS adoptions, unpublished working paper. University of Mannheim.

Doidge, C., Karolyi, A., Stulz, R., 2004. Why are foreign firms listed in the U.S. worth more? Journal of Financial Economics 71, 205-238.

Fan, J., Wong, T., 2005. Do external auditors perform a corporate governance role in emerging markets? Evidence from East Asia. Journal of Accounting Research 43, 35-72.

Ferreira, M., Matos, P., 2008. The colors of investors' money: The role of institutional investors around the world. Journal of Financial Economics 88, 499-533.

Francis, J., 2004. What do we know about audit quality? The British Accounting Review 36, 345-368.

Goyenko, R., Holden, C., Trzcinka, C., 2009. Do liquidity measures measure liquidity? Journal of Financial Economics 92, 153-181.

Grossman, S., Miller, M., 1988. Liquidity and market structure. Journal of Finance 43, 617-633.

Hameed, A., Kang, W., Viswanathan, W., 2010. Stock market declines and liquidity, forthcoming. Journal of Finance.

Hilary, G., 2010. Accounting Quality and Catastrophic Market Events, unpublished working paper. INSEAD.

Hope, O.K., Kang, T., Thomas, W., Yoo, Y., 2009. Impact of excess auditor remuneration on cost of equity capital around the world. Journal of Accounting, Auditing, and Finance 24, 177-210.

Hostak, P., Karaoglu, E., Lys, T., Yang, Y., 2009. An examination of the impact of the SarbanesOxley Act on the attractiveness of US capital markets for foreign firms, unpublished working paper. University of Massachusetts at Dartmouth.

Hutton, A., Marcus, A., Tehranian, H., 2009. Opaque financial reports, $R^{2}$, and crash risk. Journal of Financial Economics 94, 67-86.

Jin, C., Myers, S., 2006. $\mathrm{R}^{2}$ around the world: New theory and new tests. Journal of Financial Economics 79, 257-292.

Jones, J., 1991. Earnings management during import relief investigations. Journal of Accounting Research 29, 193-228.

Kamara A., Lou, X., Sadka, R., 2008. The divergence of liquidity commonality in the crosssection of stocks. Journal of Financial Economics 89, 444-466. 
Karolyi, G., Lee, A., Van Dijk, M., 2010. Common patterns in commonality in returns, liquidity, and turnover around the world, unpublished working paper. Cornell University.

Kyle, A., 1985. Continuous auctions and insider trading. Econometrica 53, 1315-1335.

Lang, M., Lins, K., Miller, D., 2004. Concentrated control, analyst following, and valuation: Do analysts matter most when investors are protected least? Journal of Accounting Research 42, 589-623.

Lang, M., Lins, K., Maffett, M., 2010. Transparency, liquidity and valuation: International evidence, unpublished working paper. University of North Carolina at Chapel Hill.

Lang, M., Lundholm, R., 1993. Cross-sectional determinants of analyst ratings of corporate disclosures. Journal of Accounting Research 31, 246-271.

Lang, M., Lundholm, R., 1996. Corporate disclosure policy and analyst behavior. The Accounting Review 71, 467-492.

Lang, M., Maffett, M., 2010. Economic effects of transparency in international equity markets: A review and suggestions for future research, unpublished working paper. University of North Carolina at Chapel Hill.

Lesmond, D. 2005. Liquidity of emerging markets. Journal of Financial Economics. 77, 411-452.

Leuz, C., 2010. Different approaches to corporate reporting regulation: How jurisdictions differ and why, unpublished working paper. University of Chicago.

Leuz, C., Nanda, D., Wysocki, P., 2003. Earnings management and investor protection: an international comparison. Journal of Financial Economics 69, 505-527.

Lou, X., Sadka, R., 2010. Liquidity level or liquidity risk? Evidence from the financial crisis, unpublished working paper. Boston College.

McCoy, C., 2003. Liquidity black holes: Testing the theory’s predictions. In: Persaud, A., (Ed.) Liquidity Black Holes: Understanding, Quantifying and Managing Financial Liquidity Risk, Vol. I. London: Haymarket House, 139-150.

Mitchell, M., Pedersen, H., Pulvino, T., 2007. Slow moving capital. American Economic Review 97, 215-220.

Moorthy, S., 2003. Liquidity in the equity market: A portfolio trader's perspective. In: Persaud, A., (Ed.) Liquidity Black Holes: Understanding, Quantifying and Managing Financial Liquidity Risk, Vol. I. London: Haymarket House, 21-40. 
Morck, R., Yeung, B., Yu, W., 2000. The information content of stock markets: Why do emerging markets have synchronous stock price movements? Journal of Financial Economics 58, 215-260.

Ng, J., 2010. The effect of information quality on liquidity risk, unpublished working paper. Massachusetts Institute of Technology.

Pástor, L., Stambaugh, R., 2003. Liquidity risk and expected stock returns. Journal of Political Economy 111, 642-685.

Persaud, A., 2003. Liquidity black holes. In: Persaud, A., (Ed.) Liquidity Black Holes: Understanding, Quantifying and Managing Financial Liquidity Risk, Vol. I. London: Haymarket House, 85-104.

Qin, Y., 2008. Liquidity and commonality in emerging markets, unpublished working paper. Massey University.

Roulstone, D., 2003. Analyst following and market liquidity. Contemporary Accounting Research 20, 552-578.

Sarkissian, S., Schill, M., 2008. Cross listing waves, unpublished working paper. McGill University.

Stock, J., Yogo, M., 2005. Testing for weak instruments in linear IV regression, Ch. 5 in J.H. Stock and D.W.K. Andrews (Eds.) Identification and Inference for Econometric Models: Essays in Honor of Thomas J. Rothenberg, Cambridge University Press.

Stoll, H., 2000. Friction. The Journal of Finance 55, 1479-1514.

Tobin, J., 1969. A general equilibrium approach to monetary theory. Journal of Money Credit and Banking 1, 15-29.

Vayanos, D., 2004. Flight to quality, flight to liquidity, and the pricing of risk, unpublished working paper. The National Bureau of Economic Research.

Yu, F., 2008. Analyst coverage and earnings management. Journal of Financial Economics 88, 245-271. 
ACCURACY = the residual value from a regression of RAW_ACCURACY on SUE and $B I A S$, where $R A W \_A C C U R A C Y$ is the absolute value of the forecast error multiplied by -1 , scaled by the stock price at the end of the prior fiscal year, where the forecast error is the $\mathrm{I} / \mathrm{B} / \mathrm{E} / \mathrm{S}$ analysts' mean annual earnings forecast less the actual earnings as reported by $\mathrm{I} / \mathrm{B} / \mathrm{E} / \mathrm{S}$

$A D R \_E X \quad=$ an indicator variable equal to one if the firm trades on a U.S. exchange during the fiscal year, and zero otherwise (hand collected from a variety of sources, including the Bank of New York, Citibank, JP Morgan and Datastream)

ADR_NEX = an indicator variable equal to one if the firm has an U.S. ADR but is not traded on a U.S. exchange during the fiscal year, and zero otherwise (hand collected from a variety of sources, including the Bank of New York, Citibank, JP Morgan and Datastream)

AGROWTH = the annual percentage change in total assets (WorldScope item 02999)

ANALYST = the number of analysts making a forecast of the firm's annual earnings, obtained from the I/B/E/S Summary File

BAVOL = the daily bid-ask spread impact measure, calculated as described in Section 5.4

BIAS = the signed value of the forecast error, scaled by stock price at the end of the prior fiscal year, where the forecast error is the $\mathrm{I} / \mathrm{B} / \mathrm{E} / \mathrm{S}$ analysts' mean annual earnings forecast less the actual earnings as reported by $\mathrm{I} / \mathrm{B} / \mathrm{E} / \mathrm{S}$
\end{abstract}

BIG5 = an indicator variable equal to one if the firm is audited by a 'Big-5' auditing firm during the fiscal year, and zero otherwise (collected from a variety of sources, including historical point-in-time Datastream data and Compustat Global)

$B M=$ annual book value of common equity (WorldScope item 03501) divided by monthly market value of common equity (Datastream item $\mathrm{P} * \mathrm{NOSH})$

CASH = cash and cash equivalents (WorldScope item 02001) scaled by total assets (WorldScope item 02999)

CLHLD = the proportion of the firm's shares that are closely held at the end of the fiscal year (WorldScope item 08021)

$\operatorname{COM}(F L, M L) \quad$ = the monthly R-squared from an OLS regression of firm liquidity on 
market liquidity, calculated as described in Section 4.1

$\operatorname{COM}(F L, M R) \quad$ = the monthly R-squared from an OLS regression of firm liquidity on market returns, calculated as described in Section 4.1

$\operatorname{COM}(F R, M L) \quad=$ the monthly R-squared from an OLS regression of firm returns on market liquidity, calculated as described in Section 4.1

DIS_SMTH

$=\mathrm{a}$ measure of the firm's discretionary earnings smoothing, calculated following Lang et al. (2010) using the average of the scaled percentile rank of DIS_SMTH1 and DIS_SMTH2, where DIS_SMTH1 \& 2 are the residual values from an earnings smoothness model described in Section 4.1

$D P I$

= the daily Amihud (2002) price impact of trade illiquidity measure, calculated as described in Section 4.1

FRET

= the monthly buy and hold return (Datastream item RI)

$I N D \_Q$

INTGAAP

ILLIQ

$L B H$

= the annual equally-weighted average $Q$ for the firm's industry, based on the firm's two-digit ICB code

= an indicator variable, based on Daske et al. (2009), that is equal to one if the firm is classified as a 'serious' adopter of an international GAAP, where a serious adopter is a firm that reports under IFRS or U.S. GAAP during the fiscal year and has an above-median aggregate transparency score (calculated excluding the INTGAAP variable) and either a) are mandated by country regulations to adopt international accounting standards, or b) voluntarily adopted international standards

= the average monthly $D P I$

$=$ the monthly probability that a firm experiences an extreme illiquidity event, or a 'liquidity black hole', calculated as described in Section 4.1

LEV = the firm's ratio of total debt (WorldScope item 03351) divided by total assets (WorldScope item 02999)

LIQSKEW $\quad$ = the monthly skewness of DPI, calculated as described in Section 4.1

LIQVOL $\quad$ = the monthly volatility of DPI, calculated as described in Section 4.1

LNTOTASS = the natural log of total assets measured in U.S. dollars (millions) (WorldScope item 02999)

LOSS_FREQ = the proportion of years that the firm experienced a loss in the last three to five fiscal years (WorldScope item 01551) 
MKTDOWN_BIG = an indicator variable equal to one if the market experienced a large downturn in the prior month, and zero otherwise, calculated as described in Section 4.1

NIEX

$=$ net income before extraordinary items (WorldScope item 01551) scaled by total assets (Worldscope item 02999)

$Q$

= the sum of total assets (WorldScope item 02999) plus market value of equity (Datastream item $\mathrm{P} * \mathrm{NOSH}$ ) minus book value of equity (Worldscope item 03501) scaled by total assets (WorldScope item 02999)

SIZE = the natural log of monthly market value of equity measured in U.S. dollars (millions) (Datastream item $\mathrm{P} * \mathrm{NOSH}$ )

STD_SALES = the standard deviation of total sales (WorldScope item 01001), calculated over the last three to five fiscal years

STDRET = the monthly standard deviation of daily stock returns (Datastream item RI)

SUE $\quad$ = unexpected earnings scaled by stock price at the end of the prior fiscal year (Datastream item P), where unexpected earnings is defined as earnings per share (Worldscope item 05201) less earnings per share from the prior fiscal year

TRANS = the average scaled percentile rank of the variables: ANALYST, ACCURACY, INTGAAP, BIG5, and (1-DIS_SMTH) 
TABLE 1

Breakdown of Sample by Country

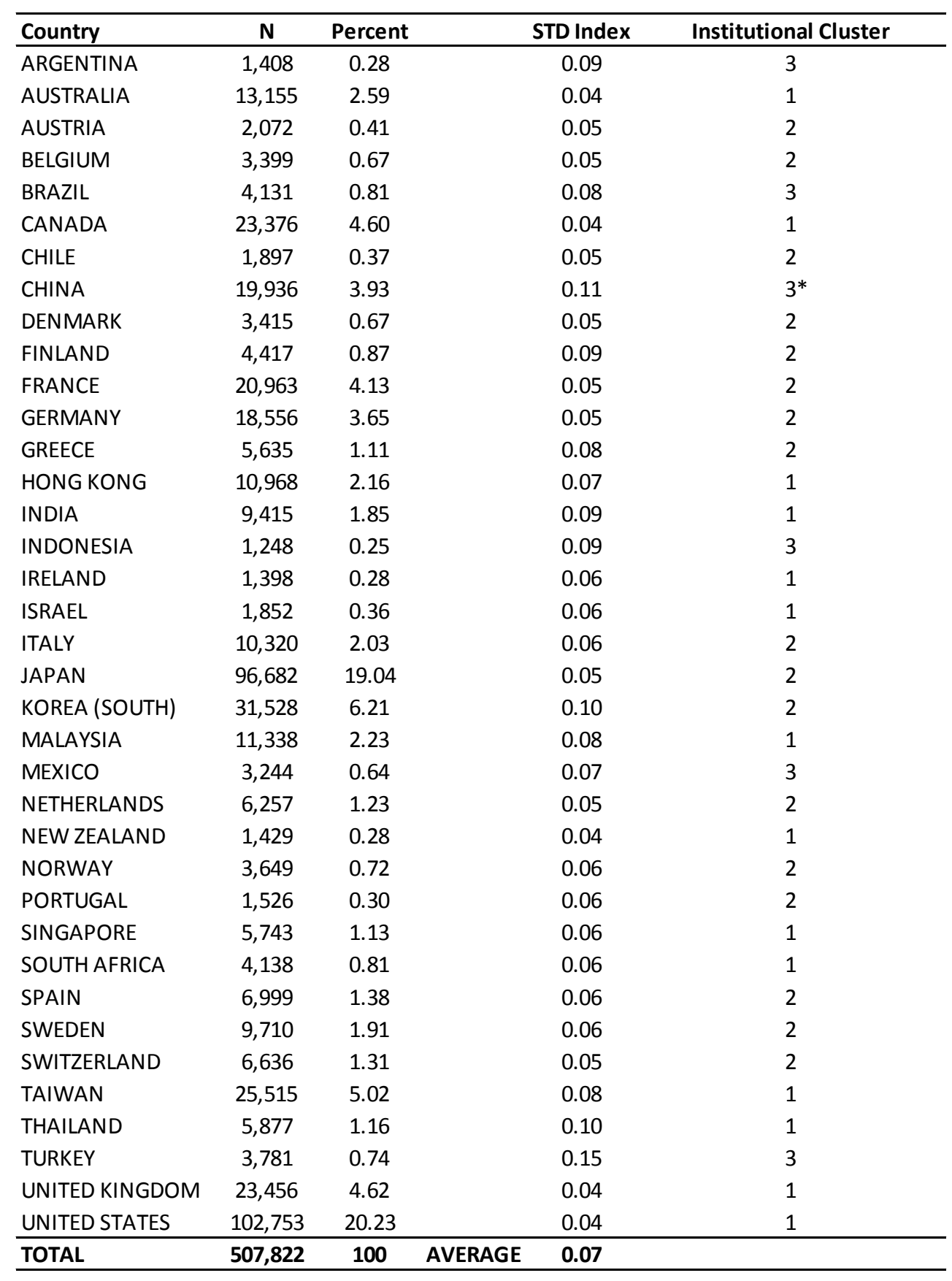

Table 1 presents the country distribution of sample firm-months during the period from 1997-2008 with sufficient data from the Worldscope and Datastream databases to estimate our least restrictive specification (Model 1 for LIQVOL in Table 4). Following the Datastream convention, we refer to Hong Kong as a country for simplicity. Any country with less than 1,000 firm-month observations is excluded from the sample. STD Index is the average standard deviation of the country's stock market index over the sample period, where stock index data are obtained from Datastream. Institutional Cluster is equal to the three-level regulatory cluster classification from Leuz (2010).

* Following prior literature, we include China in the weak institutional group although cluster data are not available in Leuz (2010). 
TABLE 2

Descriptive Statistics

\begin{tabular}{|c|c|c|c|c|c|c|}
\hline Variable & $\mathbf{N}$ & Mean & Std & P25 & Median & P75 \\
\hline LIQVOL & 507,822 & 0.488 & 2.268 & 0.002 & 0.018 & 0.141 \\
\hline LIQSKEW & 496,954 & 1.444 & 0.872 & 0.799 & 1.275 & 1.931 \\
\hline$\angle B H$ & 507,822 & 0.006 & 0.043 & 0.000 & 0.000 & 0.000 \\
\hline $\operatorname{COV}(F L, M L)$ & 498,314 & 0.194 & 0.143 & 0.083 & 0.159 & 0.271 \\
\hline $\operatorname{COV}(F L, M R)$ & 498,193 & 0.177 & 0.125 & 0.079 & 0.149 & 0.248 \\
\hline $\operatorname{COV}(F R, M L)$ & 498,726 & 0.170 & 0.119 & 0.076 & 0.143 & 0.238 \\
\hline$Q$ & 54,022 & 1.534 & 0.921 & 0.999 & 1.255 & 1.718 \\
\hline DIS_SMTH & 507,822 & 0.479 & 0.253 & 0.260 & 0.490 & 0.680 \\
\hline BIG5 & 507,822 & 0.474 & 0.499 & 0.000 & 0.000 & 1.000 \\
\hline ANALYST & 507,822 & 5.722 & 6.682 & 1.000 & 3.000 & 9.000 \\
\hline ACCURACY & 348,442 & 0.000 & 0.025 & 0.001 & 0.008 & 0.010 \\
\hline INTGAAP & 507,822 & 0.268 & 0.443 & 0.000 & 0.000 & 1.000 \\
\hline TRANS & 507,822 & 0.501 & 0.159 & 0.379 & 0.496 & 0.624 \\
\hline SIZE & 507,822 & 13.131 & 2.161 & 11.676 & 12.857 & 14.327 \\
\hline$B M$ & 507,822 & 0.949 & 1.200 & 0.332 & 0.625 & 1.119 \\
\hline STDRET & 507,822 & 0.026 & 0.014 & 0.016 & 0.023 & 0.032 \\
\hline FRET & 507,822 & 0.002 & 0.026 & -0.012 & 0.002 & 0.015 \\
\hline ILLIQ & 507,822 & 0.348 & 1.416 & 0.003 & 0.022 & 0.144 \\
\hline CLHLD & 507,822 & 28.871 & 25.036 & 1.550 & 26.380 & 48.940 \\
\hline$A D R \_E X$ & 507,822 & 0.033 & 0.178 & 0.000 & 0.000 & 0.000 \\
\hline$A D R \_N E X$ & 507,822 & 0.042 & 0.200 & 0.000 & 0.000 & 0.000 \\
\hline STD_SALES & 507,822 & 0.235 & 0.545 & 0.073 & 0.136 & 0.258 \\
\hline LOSS_FREQ & 507,822 & 0.164 & 0.251 & 0.000 & 0.000 & 0.200 \\
\hline LNTOTASS & 54,022 & 13.478 & 1.658 & 12.334 & 13.363 & 14.552 \\
\hline LEV & 54,022 & 0.524 & 0.193 & 0.390 & 0.536 & 0.661 \\
\hline $\mathrm{CASH}$ & 54,022 & 0.127 & 0.128 & 0.036 & 0.088 & 0.175 \\
\hline NIEX & 54,022 & 0.034 & 0.156 & 0.012 & 0.039 & 0.072 \\
\hline AGROWTH & 54,022 & 0.015 & 0.237 & 0.000 & 0.000 & 0.000 \\
\hline MKTDOWN_BIG & 507,822 & 0.067 & 0.251 & 0.000 & 0.000 & 0.000 \\
\hline MKTDOWN_BIG1 & 507,822 & 0.038 & 0.191 & 0.000 & 0.000 & 0.000 \\
\hline MKTDOWN_BIG2 & 507,822 & 0.029 & 0.169 & 0.000 & 0.000 & 0.000 \\
\hline
\end{tabular}

Table 2 presents descriptive statistics based on all firm-months (or firm-years for the $Q$ analysis variables) between 1997 and 2008 with sufficient data to estimate the basic regression model in which the data item is included. All variables are calculated as defined in the Appendix. 
TABLE 3

Correlation Matrices

Panel A - Dependent Variable Correlation Matrix

\begin{tabular}{lrrrrrr} 
VARIABLE & LIQVOL & LIQSKEW & \multicolumn{1}{l}{ LBH COM(FL,ML) } & COM(FL,MR) & COM(FR,ML) \\
\hline LIQVOL &. & 0.47 & 0.36 & 0.08 & 0.08 & 0.03 \\
LIQSKEW & 0.45 &. & 0.22 & 0.03 & 0.04 & -0.01 \\
LBH & 0.32 & 0.20 &. & 0.03 & 0.03 & 0.01 \\
COM(FL,ML) & 0.08 & 0.03 & 0.03 &. & 0.08 & 0.05 \\
COM(FL,MR) & 0.09 & 0.05 & 0.03 & 0.08 &. & 0.02 \\
COM(FR,ML) & 0.03 & -0.01 & 0.01 & 0.05 & 0.02 &. \\
\hline
\end{tabular}

Panel B - Independent Variable Correlation Matrix

\begin{tabular}{|c|c|c|c|c|c|c|c|c|c|c|c|c|c|c|c|}
\hline VARIABLE & DIS_SMTH & INTGAAP & BIG5 & ANALYST & ACCURACY & SIZE & $B M$ & STDRET & FRET & ILLIQ & CLHLD & ADR_EX & ADR_NEX & STD_SALES & LOSS_FREQ \\
\hline DIS_SMTH & . & -0.20 & -0.13 & -0.11 & 0.00 & -0.17 & 0.06 & 0.05 & -0.01 & 0.04 & 0.03 & -0.05 & -0.03 & 0.04 & $\quad 0.10$ \\
\hline INTGAAP & -0.20 & . & 0.39 & 0.29 & 0.10 & 0.24 & -0.13 & -0.09 & 0.01 & -0.10 & -0.14 & -0.02 & -0.06 & 0.01 & -0.05 \\
\hline BIG5 & -0.13 & 0.39 & & 0.27 & 0.04 & 0.22 & -0.07 & -0.09 & 0.00 & -0.06 & -0.17 & 0.08 & 0.01 & 0.03 & -0.04 \\
\hline ANALYST & -0.13 & 0.37 & 0.30 & . & 0.14 & 0.53 & -0.10 & -0.10 & 0.00 & -0.15 & -0.06 & 0.21 & 0.20 & -0.02 & -0.19 \\
\hline ACCURACY & -0.02 & 0.16 & 0.08 & 0.18 & . & 0.16 & -0.13 & -0.08 & 0.02 & -0.10 & -0.06 & 0.00 & 0.01 & -0.02 & -0.15 \\
\hline SIZE & -0.18 & 0.29 & 0.24 & 0.60 & 0.21 & & -0.38 & -0.17 & 0.00 & -0.25 & -0.09 & 0.22 & 0.15 & -0.03 & -0.21 \\
\hline$B M$ & 0.09 & -0.16 & -0.11 & -0.22 & -0.17 & -0.46 & . & 0.07 & 0.00 & 0.12 & 0.07 & 0.00 & 0.00 & -0.04 & 0.02 \\
\hline STDRET & 0.05 & -0.11 & -0.10 & -0.13 & -0.08 & -0.20 & 0.03 & . & 0.03 & 0.17 & -0.02 & -0.02 & -0.03 & 0.07 & 0.25 \\
\hline FRET & 0.00 & 0.01 & 0.00 & 0.01 & 0.00 & 0.01 & 0.00 & 0.01 & . & -0.01 & 0.00 & 0.00 & 0.00 & 0.00 & -0.01 \\
\hline ILLIQ & 0.15 & -0.36 & -0.28 & -0.53 & -0.23 & -0.74 & 0.36 & 0.21 & -0.02 & . & 0.05 & -0.04 & -0.03 & 0.03 & 0.15 \\
\hline CLHLD & 0.02 & -0.10 & -0.13 & 0.00 & -0.06 & -0.02 & 0.08 & -0.04 & 0.00 & 0.15 & - & -0.02 & 0.04 & 0.00 & -0.04 \\
\hline$A D R \_E X$ & -0.05 & -0.02 & 0.08 & 0.17 & 0.00 & 0.18 & -0.03 & -0.02 & 0.00 & -0.15 & -0.02 & . & -0.04 & -0.02 & 0.00 \\
\hline$A D R \_N E X$ & -0.03 & -0.06 & 0.01 & 0.18 & 0.00 & 0.15 & -0.02 & -0.03 & 0.00 & -0.12 & 0.05 & -0.04 & . & -0.02 & -0.03 \\
\hline STD_SALES & 0.02 & 0.04 & 0.07 & -0.03 & -0.06 & -0.11 & -0.16 & 0.14 & 0.01 & 0.08 & -0.02 & -0.05 & -0.07 & . & 0.07 \\
\hline LOSS_FREQ & 0.03 & -0.04 & -0.04 & -0.21 & -0.13 & -0.23 & 0.02 & 0.23 & -0.02 & 0.21 & -0.04 & 0.01 & -0.02 & 0.11 & \\
\hline
\end{tabular}

Table 3 reports Pearson correlation coefficients (above the diagonal) and Spearman coefficients (below the diagonal) for variables used in our primary analyses. Correlations that are significant at the 5\% level or better are presented in bold. 
TABLE 4

Transparency and Liquidity Volatility

\begin{tabular}{|c|c|c|c|c|c|c|}
\hline VARIABLES & $\begin{array}{c}\text { (1) } \\
\text { LIQVOL }\end{array}$ & $\begin{array}{c}\text { (2) } \\
\text { LIQVOL }\end{array}$ & $\begin{array}{c}\text { (3) } \\
\text { LIQVOL }\end{array}$ & $\begin{array}{c}\text { (4) } \\
\text { LIQVOL }\end{array}$ & $\begin{array}{c}\text { (5) } \\
\text { LIQVOL } \\
\end{array}$ & $\begin{array}{c}\text { (6) } \\
\text { LIQVOL }\end{array}$ \\
\hline SIZE & $\begin{array}{c}-1.025^{* * *} \\
(0.009)\end{array}$ & $\begin{array}{c}-1.025^{* * *} \\
(0.002)\end{array}$ & $\begin{array}{c}-1.025^{* * *} \\
(0.009)\end{array}$ & $\begin{array}{c}-0.852^{* * *} \\
(0.010)\end{array}$ & $\begin{array}{c}-1.049 * * * \\
(0.010)\end{array}$ & $\begin{array}{c}-0.970^{* * *} \\
(0.009)\end{array}$ \\
\hline$B M$ & $\begin{array}{c}-0.101^{* * *} \\
(0.011)\end{array}$ & $\begin{array}{c}-0.099 * * * \\
(0.002)\end{array}$ & $\begin{array}{c}-0.099 * * * \\
(0.011)\end{array}$ & $\begin{array}{c}-0.055^{* * *} \\
(0.010)\end{array}$ & $\begin{array}{c}-0.158^{* * *} \\
(0.013)\end{array}$ & $\begin{array}{c}-0.093^{* * *} \\
(0.010)\end{array}$ \\
\hline STDRET & $\begin{array}{c}-1.575^{* * *} \\
(0.516)\end{array}$ & $\begin{array}{c}-1.591^{* * *} \\
(0.169)\end{array}$ & $\begin{array}{c}-1.708^{* * *} \\
(0.516)\end{array}$ & $\begin{array}{c}-1.095^{* *} \\
(0.492)\end{array}$ & $\begin{array}{c}2.598^{* * *} \\
(0.604)\end{array}$ & $\begin{array}{c}-1.517^{* * *} \\
(0.508)\end{array}$ \\
\hline FRET & $\begin{array}{c}-1.353^{* * *} \\
(0.092)\end{array}$ & $\begin{array}{c}-1.350^{* * *} \\
(0.081)\end{array}$ & $\begin{array}{c}-1.342^{* * *} \\
(0.092)\end{array}$ & $\begin{array}{c}-1.321 * * * \\
(0.089)\end{array}$ & $\begin{array}{c}-1.210^{* * *} \\
(0.110)\end{array}$ & $\begin{array}{c}-1.318^{* * *} \\
(0.091)\end{array}$ \\
\hline ILLIQ & $\begin{array}{c}0.300^{* * *} \\
(0.007)\end{array}$ & $\begin{array}{c}0.300^{* * *} \\
(0.002)\end{array}$ & $\begin{array}{c}0.299 * * * \\
(0.007)\end{array}$ & $\begin{array}{c}0.287^{* * *} \\
(0.007)\end{array}$ & $\begin{array}{c}0.369^{* * *} \\
(0.013)\end{array}$ & $\begin{array}{c}0.293 * * * \\
(0.007)\end{array}$ \\
\hline CLHLD & $\begin{array}{c}0.012 * * * \\
(0.000)\end{array}$ & $\begin{array}{c}0.012^{* * *} \\
(0.000)\end{array}$ & $\begin{array}{c}0.013^{* * *} \\
(0.000)\end{array}$ & $\begin{array}{c}0.011^{* * *} \\
(0.000)\end{array}$ & $\begin{array}{c}0.015^{* * *} \\
(0.001)\end{array}$ & $\begin{array}{c}0.012^{* * *} \\
(0.000)\end{array}$ \\
\hline$A D R \_E X$ & $\begin{array}{c}-0.709 * * * \\
(0.069)\end{array}$ & $\begin{array}{c}-0.705^{* * *} \\
(0.013)\end{array}$ & $\begin{array}{c}-0.680^{* * *} \\
(0.069)\end{array}$ & $\begin{array}{c}-0.483^{* * *} \\
(0.068)\end{array}$ & $\begin{array}{c}-0.611^{* * *} \\
(0.071)\end{array}$ & $\begin{array}{c}-0.644^{* * *} \\
(0.069)\end{array}$ \\
\hline$A D R \_N E X$ & $\begin{array}{c}-0.690^{* * *} \\
(0.061)\end{array}$ & $\begin{array}{c}-0.691^{* * *} \\
(0.011)\end{array}$ & $\begin{array}{c}-0.677^{* * *} \\
(0.061)\end{array}$ & $\begin{array}{c}-0.461^{* * *} \\
(0.058)\end{array}$ & $\begin{array}{c}-0.598 * * * \\
(0.061)\end{array}$ & $\begin{array}{c}-0.633^{* * *} \\
(0.060)\end{array}$ \\
\hline STD_SALES & $\begin{array}{l}-0.013 \\
(0.014)\end{array}$ & $\begin{array}{c}-0.011^{* * *} \\
(0.004)\end{array}$ & $\begin{array}{l}-0.010 \\
(0.014)\end{array}$ & $\begin{array}{l}-0.016 \\
(0.014)\end{array}$ & $\begin{array}{l}-0.017 \\
(0.013)\end{array}$ & $\begin{array}{l}-0.015 \\
(0.014)\end{array}$ \\
\hline LOSS_FREQ & $\begin{array}{c}0.229 * * * \\
(0.046)\end{array}$ & $\begin{array}{c}0.238 * * * \\
(0.009)\end{array}$ & $\begin{array}{c}0.230 * * * \\
(0.046)\end{array}$ & $\begin{array}{c}0.131^{* * *} \\
(0.043)\end{array}$ & $\begin{array}{c}0.190 * * * \\
(0.056)\end{array}$ & $\begin{array}{c}0.133^{* * *} \\
(0.045)\end{array}$ \\
\hline DIS_SMTH & $\begin{array}{c}0.121 * * * \\
(0.038)\end{array}$ & & & & & \\
\hline INTGAAP & & $\begin{array}{c}-0.120^{* * *} \\
(0.008)\end{array}$ & & & & \\
\hline BIG5 & & & $\begin{array}{c}-0.193^{* * *} \\
(0.028)\end{array}$ & & & \\
\hline ANALYST & & & & $\begin{array}{c}-0.080^{* * *} \\
(0.003)\end{array}$ & & \\
\hline ACCURACY & & & & & $\begin{array}{c}-1.239 * * * \\
(0.332)\end{array}$ & \\
\hline TRANS & & & & & & $\begin{array}{c}-2.009 * * * \\
(0.093) \\
\end{array}$ \\
\hline Fixed Effects & $C, Y$ & $C, Y$ & $C, Y$ & $C, Y$ & $C, Y$ & $C, Y$ \\
\hline Observations & 507,822 & 507,822 & 507,822 & 507,822 & 348,442 & 507,822 \\
\hline Adjusted R-squared & 0.709 & 0.709 & 0.709 & 0.725 & 0.722 & 0.714 \\
\hline
\end{tabular}

Table 4 presents results of OLS estimation of our Transparency and Liquidity Volatility analysis using firm-level monthly observations. All variables are calculated as described in the Appendix. Robust standard errors, clustered at the firm level, are reported in parentheses. We include country $(\mathrm{C})$ and year $(\mathrm{Y})$ fixed effects in the models as indicated, but do not report the coefficients. All continuous non-logarithmic variables are truncated at the $1^{\text {st }}$ and $99^{\text {th }}$ percentiles. Statistical significance is indicated by: ${ }^{* * *} \mathrm{p}<0.01,{ }^{* *} \mathrm{p}<0.05,{ }^{*} \mathrm{p}<0.1$ (two-sided). 
TABLE 5

Transparency and Extreme Illiquidity Events

\begin{tabular}{|c|c|c|}
\hline VARIABLES & $\begin{array}{c}\text { (1) } \\
\text { LIQSKEW }\end{array}$ & $\begin{array}{l}\text { (2) } \\
\text { LBH }\end{array}$ \\
\hline \multirow[t]{2}{*}{ SIZE } & $-0.120 * * *$ & $-0.211 * * *$ \\
\hline & $(0.002)$ & $(0.008)$ \\
\hline \multirow[t]{2}{*}{$B M$} & $-0.014 * * *$ & $0.030 * * *$ \\
\hline & $(0.002)$ & $(0.010)$ \\
\hline \multirow[t]{2}{*}{ STDRET } & $-2.429 * * *$ & $-1.301^{* *}$ \\
\hline & $(0.125)$ & $(0.514)$ \\
\hline \multirow[t]{2}{*}{ FRET } & $0.097^{* *}$ & $-0.463^{* * *}$ \\
\hline & $(0.044)$ & (0.124) \\
\hline \multirow[t]{2}{*}{ ILLIQ } & $0.038 * * *$ & $0.385^{* * *}$ \\
\hline & $(0.002)$ & $(0.012)$ \\
\hline \multirow[t]{2}{*}{ CLHLD } & $0.002 * * *$ & $-0.001 * *$ \\
\hline & $(0.000)$ & $(0.001)$ \\
\hline \multirow[t]{2}{*}{$A D R \_E X$} & $-0.123 * * *$ & $0.283 * * *$ \\
\hline & $(0.015)$ & $(0.050)$ \\
\hline \multirow[t]{2}{*}{$A D R \_N E X$} & $-0.118 * * *$ & $0.227^{* * *}$ \\
\hline & $(0.013)$ & $(0.037)$ \\
\hline \multirow[t]{2}{*}{ STD_SALES } & $-0.009 * *$ & -0.016 \\
\hline & $(0.004)$ & $(0.014)$ \\
\hline \multirow[t]{2}{*}{ LOSS_FREQ } & $-0.112 * * *$ & $0.278^{* * *}$ \\
\hline & $(0.010)$ & $(0.053)$ \\
\hline \multirow[t]{2}{*}{ TRANS } & $-0.189 * * *$ & $-0.873^{* * *}$ \\
\hline & $(0.021)$ & $(0.106)$ \\
\hline Fixed Effects & $C, Y$ & $C, Y$ \\
\hline Observations & 496,954 & 507,822 \\
\hline Adjusted R-squared & 0.155 & 0.136 \\
\hline
\end{tabular}

Table 5 presents results of OLS estimation of our Transparency and Extreme Illiquidity Events analysis using firmlevel monthly observations. All variables are calculated as described in the Appendix. Robust standard errors, clustered at the firm level, are reported in parentheses. We include country (C) and year (Y) fixed effects in the models as indicated, but do not report the coefficients. All continuous non-logarithmic variables are truncated at the 1st and 99th percentiles. Statistical significance is indicated by: ${ }^{* * *} \mathrm{p}<0.01,{ }^{* *} \mathrm{p}<0.05,{ }^{*} \mathrm{p}<0.1$ (two-sided). 
TABLE 6

Transparency and Liquidity Commonality

\begin{tabular}{|c|c|c|}
\hline & (1) & (2) \\
\hline VARIABLES & $\operatorname{COM}(F L, M L)$ & $\operatorname{COM}(F L, M R)$ \\
\hline \multirow[t]{2}{*}{ SIZE } & $-0.021 * * *$ & $-0.025^{* * *}$ \\
\hline & $(0.001)$ & $(0.001)$ \\
\hline \multirow[t]{2}{*}{$B M$} & -0.002 & $-0.004 * * *$ \\
\hline & $(0.002)$ & $(0.002)$ \\
\hline \multirow[t]{2}{*}{ STDRET } & $-0.247^{* *}$ & -0.187 \\
\hline & $(0.125)$ & (0.119) \\
\hline \multirow[t]{2}{*}{ FRET } & $-0.123 * *$ & -0.072 \\
\hline & $(0.057)$ & $(0.054)$ \\
\hline \multirow[t]{2}{*}{ ILLIQ } & $0.014^{* * *}$ & $0.015^{* * *}$ \\
\hline & $(0.001)$ & $(0.001)$ \\
\hline \multirow[t]{2}{*}{ CLHLD } & 0.000 & $0.000 * * *$ \\
\hline & $(0.000)$ & $(0.000)$ \\
\hline \multirow[t]{2}{*}{$A D R \_E X$} & $-0.024 * *$ & $-0.025 * * *$ \\
\hline & $(0.010)$ & $(0.010)$ \\
\hline \multirow[t]{2}{*}{$A D R \_N E X$} & -0.008 & $-0.018^{* *}$ \\
\hline & $(0.010)$ & $(0.009)$ \\
\hline \multirow[t]{2}{*}{ STD_SALES } & -0.004 & 0.002 \\
\hline & $(0.003)$ & $(0.002)$ \\
\hline \multirow[t]{2}{*}{ LOSS_FREQ } & $0.053^{* * *}$ & $0.030 * * *$ \\
\hline & $(0.007)$ & $(0.007)$ \\
\hline \multirow[t]{2}{*}{ TRANS } & $-0.118 * * *$ & $-0.080 * * *$ \\
\hline & $(0.016)$ & $(0.015)$ \\
\hline Fixed Effects & $C, Y$ & $C, Y$ \\
\hline Observations & 498,314 & 498,193 \\
\hline Adjusted R-squared & 0.020 & 0.011 \\
\hline
\end{tabular}

Table 6 presents results of OLS estimation of our Transparency and Liquidity Commonality analysis using firmlevel monthly observations. All variables are calculated as described in the Appendix. Robust standard errors, clustered at the firm level, are reported in parentheses. We include country (C) and year (Y) fixed effects in the models as indicated, but do not report the coefficients. All continuous non-logarithmic variables are truncated at the 1st and 99th percentiles. Statistical significance is indicated by: ${ }^{* * *} \mathrm{p}<0.01,{ }^{* *} \mathrm{p}<0.05,{ }^{*} \mathrm{p}<0.1$ (two-sided). 
TABLE 7

Robustness Analyses

Panel A: BAVOL Analysis

\begin{tabular}{|c|c|c|c|c|c|}
\hline VARIABLES & $\begin{array}{c}\text { (1) } \\
\text { LIQVOL }\end{array}$ & $\begin{array}{c}\text { (2) } \\
\text { LIQSKEW }\end{array}$ & $\begin{array}{l}(3) \\
L B H\end{array}$ & $\begin{array}{c}(4) \\
\operatorname{COM}(F L, M L)\end{array}$ & $\begin{array}{c}(5) \\
\operatorname{COM}(F L, M R)\end{array}$ \\
\hline \multirow[t]{2}{*}{ SIZE } & $-1.257^{* * *}$ & $-0.093 * * *$ & $-0.491 * * *$ & $-0.004^{* * *}$ & $-0.011^{* * *}$ \\
\hline & $(0.016)$ & $(0.002)$ & $(0.015)$ & (0.001) & (0.001) \\
\hline \multirow[t]{2}{*}{$B M$} & $-0.097 * * *$ & $-0.008 * * *$ & $0.069 * * *$ & $0.007^{* * *}$ & $0.003^{* *}$ \\
\hline & $(0.015)$ & $(0.003)$ & (0.017) & $(0.001)$ & $(0.002)$ \\
\hline \multirow[t]{2}{*}{ STDRET } & $-5.257^{* * *}$ & $-0.962^{* * *}$ & 0.832 & $0.386 * * *$ & $0.328 * * *$ \\
\hline & $(0.717)$ & $(0.150)$ & $(0.843)$ & $(0.122)$ & $(0.119)$ \\
\hline \multirow[t]{2}{*}{ FRET } & $-1.879 * * *$ & $0.231 * * *$ & $-1.194^{* * *}$ & -0.040 & -0.038 \\
\hline & $(0.145)$ & $(0.057)$ & $(0.218)$ & $(0.060)$ & $(0.057)$ \\
\hline \multirow[t]{2}{*}{ ILLIQ } & $0.069 * * *$ & $0.003 * * *$ & $0.125^{* * *}$ & $0.004 * * *$ & $0.003 * * *$ \\
\hline & $(0.002)$ & $(0.000)$ & $(0.002)$ & $(0.000)$ & $(0.000)$ \\
\hline \multirow[t]{2}{*}{ CLHLD } & $0.014 * * *$ & $0.001 * * *$ & $-0.005 * * *$ & $-0.000 * * *$ & $-0.000 * * *$ \\
\hline & $(0.001)$ & $(0.000)$ & $(0.001)$ & $(0.000)$ & $(0.000)$ \\
\hline \multirow[t]{2}{*}{$A D R \_E X$} & $-1.165^{* * *}$ & $-0.093 * * *$ & $0.656 * * *$ & 0.016 & -0.001 \\
\hline & (0.119) & (0.019) & $(0.100)$ & (0.011) & (0.010) \\
\hline \multirow[t]{2}{*}{$A D R \_N E X$} & $-0.825^{* * *}$ & $-0.101 * * *$ & $0.298 * * *$ & 0.005 & 0.003 \\
\hline & $(0.088)$ & (0.017) & $(0.067)$ & (0.009) & (0.008) \\
\hline \multirow[t]{2}{*}{ STD_SALES } & -0.029 & -0.000 & $-0.056 *$ & -0.000 & 0.000 \\
\hline & $(0.023)$ & $(0.004)$ & $(0.033)$ & (0.003) & $(0.002)$ \\
\hline \multirow[t]{2}{*}{ LOSS_FREQ } & -0.002 & $-0.151^{* * *}$ & $0.175^{* *}$ & -0.006 & $-0.018 * *$ \\
\hline & $(0.069)$ & $(0.012)$ & $(0.085)$ & $(0.007)$ & $(0.007)$ \\
\hline \multirow[t]{2}{*}{ TRANS } & $-3.104^{* * *}$ & $-0.083^{* * *}$ & $-1.801 * * *$ & $-0.113^{* * *}$ & $-0.066 * * *$ \\
\hline & $(0.148)$ & $(0.028)$ & $(0.172)$ & $(0.017)$ & $(0.016)$ \\
\hline Fixed Effects & $C, Y$ & $C, Y$ & $C, Y$ & $C, Y$ & $C, Y$ \\
\hline Observations & 399,923 & 393,143 & 399,709 & 392,876 & 392,745 \\
\hline Adjusted R-squared & 0.694 & 0.109 & 0.197 & 0.007 & 0.004 \\
\hline
\end{tabular}

Table 7 Panel A presents results of OLS estimation of our bid-ask spread impact analysis using firm-level monthly observations. $L I Q V O L, L I Q S K E W, L B H, C O M(F L, M L)$ and $C O M(F L, M R)$ are calculated as described in Section 4.1 except that $B A V O L$, instead of $D P I$ is used as the underlying liquidity construct. All variables are otherwise calculated as described in the Appendix. Robust standard errors, clustered at the firm level, are reported in parentheses. We include country (C), and year (Y) fixed effects in the models as indicated, but do not report the coefficients. All continuous non-logarithmic variables are truncated at the 1st and 99th percentiles. Statistical significance is indicated by: *** $\mathrm{p}<0.01,{ }^{* *} \mathrm{p}<0.05,{ }^{*} \mathrm{p}<0.1$ (two-sided). 
TABLE 7- Continued

Robustness Analyses

Panel B: Changes Analysis

\begin{tabular}{|c|c|c|c|c|c|}
\hline VARIABLES & $\begin{array}{c}\text { (1) } \\
\Delta L I Q V O L\end{array}$ & $\begin{array}{c}\text { (2) } \\
\text { DLIQSKEW }\end{array}$ & $\begin{array}{c}\text { (3) } \\
\Delta L B H\end{array}$ & $\begin{array}{c}\text { (4) } \\
\Delta \operatorname{COM}(F L, M L)\end{array}$ & $\begin{array}{c}(5) \\
\Delta C O M(F L, M R)\end{array}$ \\
\hline \multirow[t]{2}{*}{$\triangle S I Z E$} & 0.004 & $-0.009 * *$ & $-0.024^{*}$ & $0.022^{* * *}$ & 0.005 \\
\hline & (0.009) & $(0.004)$ & (0.015) & $(0.005)$ & $(0.005)$ \\
\hline \multirow[t]{2}{*}{$\triangle B M$} & $0.225^{* * *}$ & $0.024^{* * *}$ & $0.098 * * *$ & $0.016^{* * *}$ & $0.014^{* * *}$ \\
\hline & (0.009) & $(0.003)$ & $(0.012)$ & $(0.004)$ & $(0.004)$ \\
\hline \multirow[t]{2}{*}{$\triangle S T D R E T$} & $-0.996 * * *$ & $-0.827^{* * *}$ & -0.153 & $-0.536 * *$ & $-0.795 * * *$ \\
\hline & $(0.343)$ & $(0.170)$ & $(0.653)$ & $(0.212)$ & $(0.204)$ \\
\hline \multirow[t]{2}{*}{$\triangle F R E T$} & $-0.326 * *$ & 0.009 & 0.191 & -0.024 & -0.003 \\
\hline & $(0.131)$ & $(0.073)$ & $(0.248)$ & (0.090) & (0.086) \\
\hline \multirow[t]{2}{*}{$\triangle I L L I Q$} & $-0.019 * * *$ & $-0.007 * *$ & -0.013 & 0.000 & 0.004 \\
\hline & $(0.006)$ & $(0.003)$ & $(0.013)$ & (0.003) & $(0.003)$ \\
\hline \multirow[t]{2}{*}{$\triangle C L H L D$} & $0.002 * * *$ & $0.000^{*}$ & 0.001 & $0.000^{*}$ & -0.000 \\
\hline & $(0.000)$ & $(0.000)$ & (0.001) & $(0.000)$ & (0.000) \\
\hline \multirow[t]{2}{*}{$\triangle A D R \_E X$} & 0.031 & -0.019 & 0.041 & $0.068 * *$ & 0.009 \\
\hline & (0.049) & $(0.024)$ & $(0.045)$ & $(0.032)$ & $(0.028)$ \\
\hline \multirow[t]{2}{*}{$\triangle A D R \_N E X$} & 0.021 & -0.005 & $0.076^{*}$ & $0.055^{*}$ & 0.028 \\
\hline & $(0.040)$ & (0.021) & $(0.046)$ & (0.029) & (0.029) \\
\hline \multirow[t]{2}{*}{$\triangle S T D \_S A L E S$} & 0.006 & -0.001 & 0.002 & -0.016 & -0.015 \\
\hline & $(0.026)$ & (0.008) & $(0.033)$ & (0.014) & (0.014) \\
\hline \multirow[t]{2}{*}{$\triangle L O S S \_F R E Q$} & $0.266 * * *$ & $0.055^{* *}$ & $0.473 * * *$ & -0.003 & 0.006 \\
\hline & $(0.049)$ & $(0.023)$ & $(0.088)$ & $(0.028)$ & $(0.027)$ \\
\hline \multirow[t]{2}{*}{$\triangle T R A N S$} & $-0.592 * * *$ & $-0.067 * *$ & $-0.324 * * *$ & $-0.091 * *$ & $-0.073 *$ \\
\hline & $(0.061)$ & $(0.033)$ & $(0.106)$ & $(0.043)$ & $(0.040)$ \\
\hline Fixed Effects & $C, Y$ & $C, Y$ & $C, Y$ & $C, Y$ & $\mathrm{C}, \mathrm{Y}$ \\
\hline Observations & 40,762 & 40,726 & 40,762 & 40,708 & 40,701 \\
\hline Adjusted R-squared & 0.298 & 0.011 & 0.011 & 0.005 & 0.003 \\
\hline
\end{tabular}

Table 7 Panel B presents results of OLS estimation of our Changes analysis using firm-level annual observations. A $\Delta$ prefix indicates that the first-differences annual change in the variable is included in the regression. All variables are otherwise calculated as described in the Appendix. Robust standard errors, clustered at the firm level, are reported in parentheses. We include country (C) and year (Y) fixed effects in the models as indicated, but do not report the coefficients. All continuous non-logarithmic variables are truncated at the 1st and 99th percentiles. Statistical significance is indicated by: ${ }^{* * *} \mathrm{p}<0.01,{ }^{* *} \mathrm{p}<0.05,{ }^{*} \mathrm{p}<0.1$ (two-sided). 
TABLE 8

Transparency, Liquidity Uncertainty and Country-Level Institutions

\begin{tabular}{|c|c|c|c|c|c|}
\hline VARIABLES & $\begin{array}{c}\text { (1) } \\
\text { LIQVOL }\end{array}$ & $\begin{array}{c}\text { (2) } \\
\text { LIQSKEW }\end{array}$ & $\begin{array}{c}(3) \\
L B H\end{array}$ & $\begin{array}{c}(4) \\
\operatorname{COM}(F L, M L)\end{array}$ & $\begin{array}{c}(5) \\
\operatorname{COM}(F L, M R)\end{array}$ \\
\hline \multirow[t]{2}{*}{ SIZE } & $-0.969 * * *$ & $-0.120 * * *$ & $-0.213^{* * *}$ & $-0.021^{* * *}$ & $-0.025^{* * *}$ \\
\hline & $(0.009)$ & $(0.002)$ & $(0.008)$ & $(0.001)$ & $(0.001)$ \\
\hline \multirow[t]{2}{*}{$B M$} & $-0.096 * * *$ & $-0.014 * * *$ & $0.029 * * *$ & -0.002 & $-0.005^{* * *}$ \\
\hline & (0.010) & (0.002) & $(0.010)$ & $(0.002)$ & $(0.002)$ \\
\hline \multirow[t]{2}{*}{ STDRET } & $-1.430 * * *$ & $-2.416^{* * *}$ & $-1.322^{* *}$ & $-0.227^{*}$ & -0.190 \\
\hline & $(0.508)$ & $(0.125)$ & $(0.520)$ & $(0.125)$ & (0.119) \\
\hline \multirow[t]{2}{*}{ FRET } & $-1.320 * * *$ & $0.098^{* *}$ & $-0.460 * * *$ & $-0.127^{* *}$ & -0.073 \\
\hline & $(0.091)$ & $(0.044)$ & $(0.125)$ & $(0.057)$ & (0.054) \\
\hline \multirow[t]{2}{*}{ ILLIQ } & $0.293 * * *$ & $0.038 * * *$ & $0.387 * * *$ & $0.014^{* * *}$ & $0.015^{* * *}$ \\
\hline & $(0.007)$ & $(0.002)$ & $(0.012)$ & $(0.001)$ & $(0.001)$ \\
\hline \multirow[t]{2}{*}{ CLHLD } & $0.012^{* * *}$ & $0.002 * * *$ & $-0.001^{* *}$ & 0.000 & $0.000^{* * *}$ \\
\hline & $(0.000)$ & $(0.000)$ & $(0.001)$ & $(0.000)$ & $(0.000)$ \\
\hline \multirow[t]{2}{*}{$A D R \_E X$} & $-0.674 * * *$ & $-0.121 * * *$ & $0.280 * * *$ & $-0.025^{* *}$ & $-0.027 * * *$ \\
\hline & $(0.070)$ & $(0.015)$ & $(0.050)$ & $(0.010)$ & $(0.010)$ \\
\hline \multirow[t]{2}{*}{$A D R \_N E X$} & $-0.627^{* * *}$ & $-0.115^{* * *}$ & $0.237^{* * *}$ & -0.007 & $-0.018^{* *}$ \\
\hline & (0.059) & $(0.013)$ & $(0.037)$ & $(0.010)$ & $(0.009)$ \\
\hline \multirow[t]{2}{*}{ STD_SALES } & -0.017 & $-0.009 * *$ & -0.015 & -0.004 & 0.002 \\
\hline & $(0.015)$ & $(0.004)$ & $(0.014)$ & $(0.003)$ & $(0.002)$ \\
\hline \multirow[t]{2}{*}{ LOSS_FREQ } & $0.124 * * *$ & $-0.112 * * *$ & $0.282 * * *$ & $0.053^{* * *}$ & $0.030 * * *$ \\
\hline & $(0.045)$ & $(0.010)$ & $(0.053)$ & $(0.007)$ & $(0.007)$ \\
\hline \multirow[t]{2}{*}{ SUB_TRANS } & $-1.131 * * *$ & $-0.051 * * *$ & $-0.320 * * *$ & $-0.033^{* *}$ & $-0.037 * *$ \\
\hline & $(0.084)$ & $(0.020)$ & $(0.089)$ & $(0.015)$ & $(0.015)$ \\
\hline \multirow[t]{2}{*}{ SUB_TRANS*WEAK } & $-0.383 * * *$ & $-0.098 * * *$ & $-0.250 *$ & $-0.068 * * *$ & -0.030 \\
\hline & $(0.112)$ & $(0.026)$ & $(0.128)$ & $(0.021)$ & $(0.019)$ \\
\hline \multirow[t]{2}{*}{ COMP_TRANS } & $-0.380 * * *$ & $-0.064 * * *$ & $-0.488 * * *$ & $-0.032^{* * *}$ & $-0.022^{*}$ \\
\hline & $(0.065)$ & $(0.016)$ & $(0.110)$ & (0.011) & $(0.012)$ \\
\hline \multirow[t]{2}{*}{ COMP_TRANS*WEAK } & $0.414^{* * *}$ & $0.045^{* *}$ & $0.432 * * *$ & 0.025 & $0.033^{* *}$ \\
\hline & $(0.087)$ & $(0.021)$ & $(0.121)$ & $(0.016)$ & $(0.015)$ \\
\hline Fixed Effects & $C, Y$ & $C, Y$ & $C, Y$ & $C, Y$ & $\mathrm{C}, \mathrm{Y}$ \\
\hline Observations & 496,954 & 496,954 & 507,822 & 498,314 & 498,193 \\
\hline Adjusted R-squared & 0.155 & 0.155 & 0.137 & 0.020 & 0.011 \\
\hline
\end{tabular}

Table 8 presents results of OLS estimation of our Transparency, Liquidity Uncertainty and Country-level Institutional analysis using firm-level monthly observations. WEAK is an indicator variable equal to one if a firm is in Institutional Cluster 2 or 3, and zero otherwise. All variables are otherwise calculated as described in the Appendix. Robust standard errors, clustered at the firm level, are reported in parentheses. We include country (C) and year (Y) fixed effects in the models as indicated, but do not report the coefficients. All continuous nonlogarithmic variables are truncated at the 1st and 99th percentiles. Statistical significance is indicated by: $* * *$ $\mathrm{p}<0.01,{ }^{* *} \mathrm{p}<0.05,{ }^{*} \mathrm{p}<0.1$ (two-sided). 
TABLE 9

Transparency, Liquidity Uncertainty and Crises

\begin{tabular}{|c|c|c|c|c|c|c|c|c|c|c|}
\hline VARIABLES & $\begin{array}{c}\text { (1) } \\
\text { LIQVOL }\end{array}$ & $\begin{array}{c}\text { (2) } \\
\text { LIQVOL }\end{array}$ & $\begin{array}{c}\text { (3) } \\
\text { LIQSKEW }\end{array}$ & $\begin{array}{c}\text { (4) } \\
\text { LIQSKEW }\end{array}$ & $\begin{array}{l}(5) \\
L B H\end{array}$ & $\begin{array}{l}(6) \\
L B H\end{array}$ & $\begin{array}{c}\text { (7) } \\
\operatorname{COM}(F L, M L)\end{array}$ & $\begin{array}{c}(8) \\
\operatorname{COM}(F L, M L)\end{array}$ & $\begin{array}{c}\text { (9) } \\
\operatorname{COM}(F L, M R)\end{array}$ & $\begin{array}{c}(10) \\
\operatorname{COM}(F L, M R)\end{array}$ \\
\hline SIZE & $\begin{array}{c}-0.971^{* * *} \\
(0.009)\end{array}$ & $\begin{array}{c}-0.971^{* * *} \\
(0.009)\end{array}$ & $\begin{array}{c}-0.120^{* * *} \\
(0.002)\end{array}$ & $\begin{array}{c}-0.120^{* * *} \\
(0.002)\end{array}$ & $\begin{array}{c}-0.212^{* * *} \\
(0.008)\end{array}$ & $\begin{array}{c}-0.212^{* * *} \\
(0.008)\end{array}$ & $\begin{array}{c}-0.021^{* * *} \\
(0.001)\end{array}$ & $\begin{array}{c}-0.021 * * * \\
(0.001)\end{array}$ & $\begin{array}{c}-0.025^{* * *} \\
(0.001)\end{array}$ & $\begin{array}{c}-0.025^{* * *} \\
(0.001)\end{array}$ \\
\hline$B M$ & $\begin{array}{c}-0.094^{* * *} \\
(0.010)\end{array}$ & $\begin{array}{c}-0.094^{* * *} \\
(0.010)\end{array}$ & $\begin{array}{c}-0.014^{* * *} \\
(0.002)\end{array}$ & $\begin{array}{c}-0.014^{* * *} \\
(0.002)\end{array}$ & $\begin{array}{c}0.029 * * * \\
(0.010)\end{array}$ & $\begin{array}{c}0.029 * * * \\
(0.010)\end{array}$ & $\begin{array}{l}-0.002 \\
(0.002)\end{array}$ & $\begin{array}{l}-0.002 \\
(0.002)\end{array}$ & $\begin{array}{c}-0.004^{* * *} \\
(0.002)\end{array}$ & $\begin{array}{c}-0.004^{* * *} \\
(0.002)\end{array}$ \\
\hline STDRET & $\begin{array}{c}-1.538^{* * *} \\
(0.508)\end{array}$ & $\begin{array}{c}-1.590^{* * *} \\
(0.508)\end{array}$ & $\begin{array}{c}-2.417^{* * *} \\
(0.125)\end{array}$ & $\begin{array}{c}-2.416^{* * *} \\
(0.125)\end{array}$ & $\begin{array}{c}-1.250^{* *} \\
(0.515)\end{array}$ & $\begin{array}{c}-1.302^{* *} \\
(0.515)\end{array}$ & $\begin{array}{c}-0.199 \\
(0.125)\end{array}$ & $\begin{array}{l}-0.202 \\
(0.125)\end{array}$ & $\begin{array}{c}-0.160 \\
(0.119)\end{array}$ & $\begin{array}{l}-0.162 \\
(0.119)\end{array}$ \\
\hline FRET & $\begin{array}{c}-1.307^{* * *} \\
(0.091)\end{array}$ & $\begin{array}{c}-1.293^{* * *} \\
(0.091)\end{array}$ & $\begin{array}{c}0.099 * * \\
(0.044)\end{array}$ & $\begin{array}{c}0.098^{* *} \\
(0.044)\end{array}$ & $\begin{array}{c}-0.448 * * * \\
(0.124)\end{array}$ & $\begin{array}{c}-0.437^{* * *} \\
(0.124)\end{array}$ & $\begin{array}{c}-0.118^{* *} \\
(0.057)\end{array}$ & $\begin{array}{c}-0.117^{* *} \\
(0.057)\end{array}$ & $\begin{array}{l}-0.070 \\
(0.054)\end{array}$ & $\begin{array}{l}-0.070 \\
(0.054)\end{array}$ \\
\hline ILLIQ & $\begin{array}{c}0.293 * * * \\
(0.007)\end{array}$ & $\begin{array}{c}0.293 * * * \\
(0.007)\end{array}$ & $\begin{array}{c}0.038^{* * *} \\
(0.002)\end{array}$ & $\begin{array}{c}0.038^{* * *} \\
(0.002)\end{array}$ & $\begin{array}{c}0.385^{* * *} \\
(0.012)\end{array}$ & $\begin{array}{c}0.385^{* * *} \\
(0.012)\end{array}$ & $\begin{array}{c}0.014^{* * *} \\
(0.001)\end{array}$ & $\begin{array}{c}0.014 * * * \\
(0.001)\end{array}$ & $\begin{array}{c}0.015 * * * \\
(0.001)\end{array}$ & $\begin{array}{c}0.015 * * * \\
(0.001)\end{array}$ \\
\hline CLHLD & $\begin{array}{c}0.012^{* * *} \\
(0.000)\end{array}$ & $\begin{array}{c}0.012^{* * *} \\
(0.000)\end{array}$ & $\begin{array}{c}0.002^{* * *} \\
(0.000)\end{array}$ & $\begin{array}{c}0.002^{* * *} \\
(0.000)\end{array}$ & $\begin{array}{c}-0.001^{* *} \\
(0.001)\end{array}$ & $\begin{array}{c}-0.001 * * \\
(0.001)\end{array}$ & $\begin{array}{c}0.000 \\
(0.000)\end{array}$ & $\begin{array}{c}0.000 \\
(0.000)\end{array}$ & $\begin{array}{c}0.000^{* * *} \\
(0.000)\end{array}$ & $\begin{array}{c}0.000^{* * *} \\
(0.000)\end{array}$ \\
\hline$A D R_{-} E X$ & $\begin{array}{c}-0.646 * * * \\
(0.069)\end{array}$ & $\begin{array}{c}-0.647^{* * *} \\
(0.069)\end{array}$ & $\begin{array}{c}-0.123^{* * *} \\
(0.015)\end{array}$ & $\begin{array}{c}-0.123^{* * *} \\
(0.015)\end{array}$ & $\begin{array}{c}0.281^{* * *} \\
(0.050)\end{array}$ & $\begin{array}{c}0.281^{* * *} \\
(0.050)\end{array}$ & $\begin{array}{c}-0.024^{* *} \\
(0.010)\end{array}$ & $\begin{array}{c}-0.024^{* *} \\
(0.010)\end{array}$ & $\begin{array}{c}-0.025^{* * *} \\
(0.010)\end{array}$ & $\begin{array}{c}-0.025^{* * *} \\
(0.010)\end{array}$ \\
\hline$A D R \_N E X$ & $\begin{array}{c}-0.632^{* * *} \\
(0.060)\end{array}$ & $\begin{array}{c}-0.632^{* * *} \\
(0.060)\end{array}$ & $\begin{array}{c}-0.118^{* * *} \\
(0.013)\end{array}$ & $\begin{array}{c}-0.118^{* * *} \\
(0.013)\end{array}$ & $\begin{array}{c}0.228 * * * \\
(0.037)\end{array}$ & $\begin{array}{c}0.228 * * * \\
(0.037)\end{array}$ & $\begin{array}{c}-0.008 \\
(0.010)\end{array}$ & $\begin{array}{c}-0.009 \\
(0.010)\end{array}$ & $\begin{array}{c}-0.018^{* *} \\
(0.009)\end{array}$ & $\begin{array}{c}-0.018^{* *} \\
(0.009)\end{array}$ \\
\hline STD_SALES & $\begin{array}{l}-0.016 \\
(0.014)\end{array}$ & $\begin{array}{c}-0.016 \\
(0.014)\end{array}$ & $\begin{array}{c}-0.009^{* *} \\
(0.004)\end{array}$ & $\begin{array}{c}-0.009 * * \\
(0.004)\end{array}$ & $\begin{array}{l}-0.016 \\
(0.014)\end{array}$ & $\begin{array}{l}-0.016 \\
(0.014)\end{array}$ & $\begin{array}{c}-0.004 \\
(0.003)\end{array}$ & $\begin{array}{c}-0.004 \\
(0.003)\end{array}$ & $\begin{array}{c}0.002 \\
(0.002)\end{array}$ & $\begin{array}{c}0.002 \\
(0.002)\end{array}$ \\
\hline LOSS_FREQ & $\begin{array}{c}0.136^{* * *} \\
(0.045)\end{array}$ & $\begin{array}{c}0.137 * * * \\
(0.045)\end{array}$ & $\begin{array}{c}-0.113^{* * *} \\
(0.010)\end{array}$ & $\begin{array}{c}-0.113^{* * *} \\
(0.010)\end{array}$ & $\begin{array}{c}0.279 * * * \\
(0.053)\end{array}$ & $\begin{array}{c}0.280^{* * *} \\
(0.053)\end{array}$ & $\begin{array}{c}0.052^{* * *} \\
(0.007)\end{array}$ & $\begin{array}{c}0.052^{* * *} \\
(0.007)\end{array}$ & $\begin{array}{c}0.030 * * * \\
(0.007)\end{array}$ & $\begin{array}{c}0.030^{* * *} \\
(0.007)\end{array}$ \\
\hline TRANS & $\begin{array}{c}-1.961 * * * \\
(0.093)\end{array}$ & $\begin{array}{c}-1.957^{* * *} \\
(0.093)\end{array}$ & $\begin{array}{c}-0.181 * * * \\
(0.021)\end{array}$ & $\begin{array}{c}-0.181 * * * \\
(0.021)\end{array}$ & $\begin{array}{c}-0.812^{* * *} \\
(0.106)\end{array}$ & $\begin{array}{c}-0.810^{* * *} \\
(0.106)\end{array}$ & $\begin{array}{c}-0.094^{* * *} \\
(0.016)\end{array}$ & $\begin{array}{c}-0.094^{* * *} \\
(0.016)\end{array}$ & $\begin{array}{c}-0.070^{* * *} \\
(0.015)\end{array}$ & $\begin{array}{c}-0.070^{* * *} \\
(0.015)\end{array}$ \\
\hline MKTDOWN_BIG & $\begin{array}{c}0.838 * * * \\
(0.032)\end{array}$ & & $\begin{array}{c}0.072 * * * \\
(0.016)\end{array}$ & & $\begin{array}{c}0.722 * * * \\
(0.056)\end{array}$ & & $\begin{array}{c}0.159 * * * \\
(0.021)\end{array}$ & & $\begin{array}{c}0.038^{* *} \\
(0.019)\end{array}$ & \\
\hline MKTDOWN_BIG1 & & $\begin{array}{c}0.745 * * * \\
(0.039)\end{array}$ & & $\begin{array}{c}0.053^{* * *} \\
(0.020)\end{array}$ & & $\begin{array}{c}0.500^{* * *} \\
(0.069)\end{array}$ & & $\begin{array}{c}0.134^{* * *} \\
(0.028)\end{array}$ & & $\begin{array}{c}0.006 \\
(0.025)\end{array}$ \\
\hline MKTDOWN_BIG2 & & $\begin{array}{c}1.046 * * * \\
(0.042)\end{array}$ & & $\begin{array}{c}0.091 * * * \\
(0.023)\end{array}$ & & $\begin{array}{c}1.070 * * * \\
(0.091)\end{array}$ & & $\begin{array}{c}0.193 * * * \\
(0.032)\end{array}$ & & $\begin{array}{c}0.079 * * * \\
(0.029)\end{array}$ \\
\hline MKTDOWN_BIG*TRANS & $\begin{array}{c}-0.692^{* * *} \\
(0.060)\end{array}$ & & $\begin{array}{c}-0.119 * * * \\
(0.028)\end{array}$ & & $\begin{array}{c}-0.901 * * * \\
(0.095)\end{array}$ & & $\begin{array}{c}-0.361 * * * \\
(0.039)\end{array}$ & & $\begin{array}{c}-0.159 * * * \\
(0.035)\end{array}$ & \\
\hline MKTDOWN_BIG1 *TRANS & & $\begin{array}{c}-0.699 * * * \\
(0.074)\end{array}$ & & $\begin{array}{c}-0.070^{*} \\
(0.037)\end{array}$ & & $\begin{array}{c}-0.605^{* * *} \\
(0.117)\end{array}$ & & $\begin{array}{c}-0.316 * * * \\
(0.053)\end{array}$ & & $\begin{array}{c}-0.096^{* *} \\
(0.048)\end{array}$ \\
\hline MKTDOWN_BIG2 *TRANS & & $\begin{array}{c}-0.840 * * * \\
(0.074)\end{array}$ & & $\begin{array}{c}-0.168 * * * \\
(0.039)\end{array}$ & & $\begin{array}{c}-1.370 * * * \\
(0.148)\end{array}$ & & $\begin{array}{c}-0.418^{* * *} \\
(0.057)\end{array}$ & & $\begin{array}{c}-0.234^{* * *} \\
(0.051)\end{array}$ \\
\hline BIG2-BIG1 Difference (P-Value) & & $\begin{array}{c}0.141^{* *} \\
(0.04) \\
\end{array}$ & & $\begin{array}{c}0.098^{* *} \\
(0.03) \\
\end{array}$ & & $\begin{array}{c}0.765^{* * *} \\
(0.00) \\
\end{array}$ & & $\begin{array}{c}0.102 * \\
(0.08) \\
\end{array}$ & & $\begin{array}{c}0.138^{* *} \\
(0.02) \\
\end{array}$ \\
\hline Fixed Effects & $C, Y$ & $C, Y$ & $C, Y$ & $C, Y$ & $C, Y$ & $C, Y$ & $C, Y$ & $C, Y$ & $C, Y$ & $C, Y$ \\
\hline Observations & 507,822 & 507,822 & 496,954 & 496,954 & 507,814 & 507,814 & 498,314 & 498,314 & 498,193 & 498,193 \\
\hline Adjusted R-squared & 0.715 & 0.716 & 0.155 & 0.155 & 0.137 & 0.137 & 0.020 & 0.020 & 0.011 & 0.011 \\
\hline
\end{tabular}


Table 9 presents results of OLS estimation of our Transparency, Liquidity Uncertainty and Crises analysis using firm-level monthly observations. All variables are calculated as described in the Appendix. Robust standard errors, clustered at the firm level, are reported in parentheses. We include country (C) and year (Y) fixed effects in the models as indicated, but do not report the coefficients. All continuous non-logarithmic variables are truncated at the 1st and 99th percentiles. P-values (one-sided) are presented for tests of the difference between the MKTDOWN_BIG2*TRANS and the MKTDOWN_BIG1*TRANS coefficients. All other statistical significance is indicated by: ${ }^{* * *} \mathrm{p}<0.01,{ }^{* *} \mathrm{p}<0.05, * \mathrm{p}<0.1$ (two-sided). 
TABLE 10

Liquidity Variation, Covariation and Valuation

\begin{tabular}{|c|c|c|c|c|c|c|}
\hline & (1) & (2) & (3) & (4) & (5) & (6) \\
\hline VARIABLES & $Q$ & $Q$ & $Q$ & $Q$ & $Q$ & $Q$ \\
\hline \multirow[t]{2}{*}{ LNTOTASS } & $-0.077^{* * *}$ & $-0.110 * * *$ & $-0.091 * * *$ & $-0.076 * * *$ & $-0.076 * * *$ & $-0.122^{* * *}$ \\
\hline & $(0.006)$ & $(0.006)$ & $(0.006)$ & $(0.006)$ & $(0.006)$ & $(0.006)$ \\
\hline \multirow[t]{2}{*}{ LEV } & 0.040 & 0.053 & 0.049 & 0.042 & 0.043 & 0.068 \\
\hline & $(0.045)$ & $(0.044)$ & (0.044) & $(0.045)$ & $(0.045)$ & (0.044) \\
\hline \multirow[t]{2}{*}{$\mathrm{CASH}$} & $1.511^{* * *}$ & $1.470 * * *$ & $1.495^{* * *}$ & $1.517^{* * *}$ & $1.518^{* * *}$ & $1.455^{* * *}$ \\
\hline & $(0.082)$ & $(0.080)$ & $(0.081)$ & $(0.082)$ & $(0.082)$ & $(0.079)$ \\
\hline \multirow[t]{2}{*}{ NIEX } & $0.580 * * *$ & $0.640 * * *$ & $0.569 * * *$ & $0.592^{* * *}$ & $0.599 * * *$ & $0.604^{* * *}$ \\
\hline & $(0.132)$ & (0.136) & (0.131) & (0.134) & (0.134) & (0.132) \\
\hline \multirow[t]{2}{*}{$I N D \_Q$} & $0.139 * * *$ & $0.129 * * *$ & $0.142^{* * *}$ & $0.143^{* * *}$ & $0.142^{* * *}$ & $0.127^{* * *}$ \\
\hline & $(0.015)$ & (0.015) & $(0.015)$ & (0.015) & $(0.015)$ & (0.014) \\
\hline \multirow[t]{2}{*}{ AGROWTH } & 0.009 & 0.009 & 0.010 & 0.011 & 0.010 & 0.009 \\
\hline & (0.008) & $(0.009)$ & $(0.008)$ & $(0.008)$ & $(0.008)$ & $(0.008)$ \\
\hline \multirow[t]{2}{*}{$A D R \_E X$} & $0.216^{* * *}$ & $0.167^{* * *}$ & $0.242^{* * *}$ & $0.211^{* * *}$ & $0.208^{* * *}$ & $0.188^{* * *}$ \\
\hline & $(0.048)$ & (0.047) & (0.048) & $(0.048)$ & (0.048) & $(0.048)$ \\
\hline \multirow[t]{2}{*}{$A D R \_N E X$} & $0.193^{* * *}$ & $0.150 * * *$ & $0.214^{* * *}$ & $0.191^{* * *}$ & $0.192^{* * *}$ & $0.166^{* * *}$ \\
\hline & $(0.036)$ & $(0.035)$ & $(0.037)$ & $(0.036)$ & (0.036) & (0.035) \\
\hline \multirow[t]{2}{*}{ A_ILLIQ } & $-0.040 * * *$ & $-0.049 * * *$ & $-0.041 * * *$ & $-0.057 * * *$ & $-0.056 * * *$ & ${ }^{*}-0.037^{* * *}$ \\
\hline & $(0.003)$ & $(0.004)$ & $(0.004)$ & (0.004) & (0.004) & $(0.003)$ \\
\hline \multirow[t]{2}{*}{ A_LIQVOL } & $-0.026 * * *$ & & & & & $-0.006^{* *}$ \\
\hline & $(0.002)$ & & & & & $(0.002)$ \\
\hline \multirow[t]{2}{*}{ A_LIQSKEW } & & $-0.308 * * *$ & & & & $-0.267 * * *$ \\
\hline & & $(0.012)$ & & & & $(0.012)$ \\
\hline \multirow[t]{2}{*}{$A \_L B H$} & & & $-0.042 * * *$ & & & $-0.023 * * *$ \\
\hline & & & $(0.002)$ & & & $(0.003)$ \\
\hline \multirow[t]{2}{*}{ A_COM(FL,ML) } & & & & $-0.096 * * *$ & & $-0.073 * * *$ \\
\hline & & & & $(0.008)$ & & $(0.008)$ \\
\hline \multirow[t]{2}{*}{ A_COM(FR,ML) } & & & & & $-0.103^{* * *}$ & $-0.066^{* * *}$ \\
\hline & & & & & $(0.009)$ & $(0.009)$ \\
\hline Fixed Effects & $C, Y$ & $C, Y$ & $C, Y$ & $C, Y$ & $C, Y$ & $C, Y$ \\
\hline Observations & 54,002 & 53,964 & 53,994 & 53,936 & 53,939 & 53,834 \\
\hline Adjusted R-squared & 0.223 & 0.241 & 0.229 & 0.222 & 0.222 & 0.248 \\
\hline
\end{tabular}

Table 10 presents results of OLS estimation of our Liquidity Variation, Covariation and Valuation analysis using firm-level annual observations. The prefix $A_{-}$indicates that the included variable is an annual average of the underlying monthly variable. All other variables are otherwise calculated as described in the Appendix. Robust standard errors, clustered at the firm level, are reported in parentheses. We include country (C) and year (Y) fixed effects in the models as indicated, but do not report the coefficients. All continuous non-logarithmic variables are truncated at the 1st and 99th percentiles. Statistical significance is indicated by: ${ }^{* * *} \mathrm{p}<0.01,{ }^{* *} \mathrm{p}<0.05,{ }^{*} \mathrm{p}<0.1$ (two-sided). 
FIGURE 1

Residual Liquidity Volatility by Transparency Group

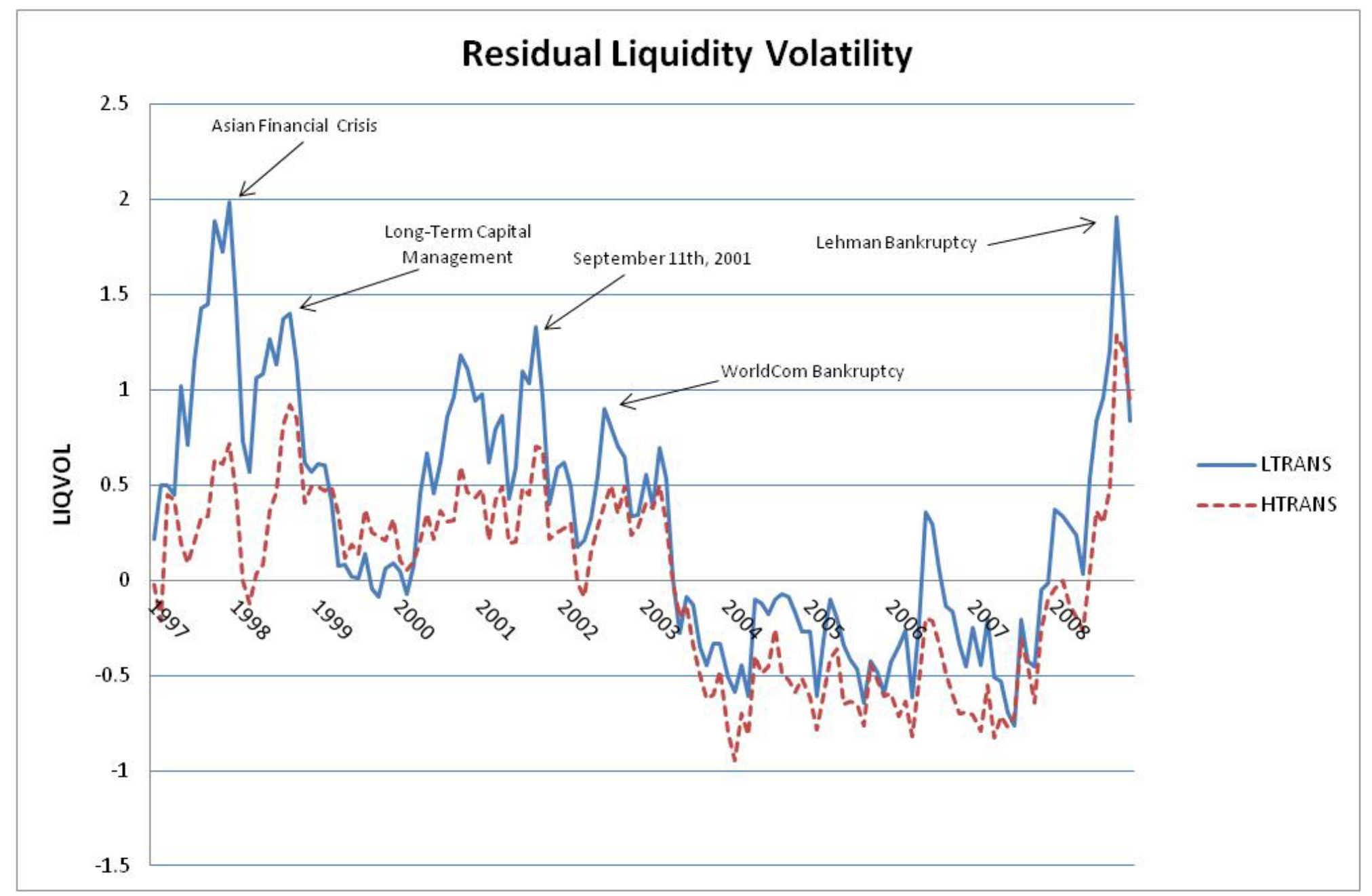

Figure 1 depicts a time-series graph of residual liquidity volatility for high and low transparency groups. A firm is classified as high transparency (HTRANS) if it has a TRANS value higher than the sample median during a particular year, and low transparency (LTRANS) otherwise. Residual liquidity is the residual value from a regression of $L I Q V O L$ on SIZE, BM, STDRET, FRET, ILLIQ, CLHLD, ADR_EX, ADR_NEX, STD_SALES, LOSS_FREQ and country fixed effects. 